Article

\title{
An Efficient Greener Approach for $N$-acylation of Amines in Water Using Benzotriazole Chemistry
}

\author{
Tarek S. Ibrahim ${ }^{1,2}$, Israa A. Seliem ${ }^{2,3}$ (), Siva S. Panda ${ }^{3, *(D)}$, Amany M. M. Al-Mahmoudy ${ }^{2}$, \\ Zakaria K. M. Abdel-Samii ${ }^{2}$, Nabil A. Alhakamy ${ }^{4}{ }^{\circledR}$, Hani Z. Asfour ${ }^{5}$ and Mohamed Elagawany ${ }^{6}$ \\ 1 Department of Pharmaceutical Chemistry, Faculty of Pharmacy, King Abdulaziz University, \\ Jeddah 21589, Saudi Arabia; tmabrahem@kau.edu.sa \\ 2 Department of Pharmaceutical Organic Chemistry, Faculty of Pharmacy, Zagazig University, \\ Zagazig 44519, Egypt; isliem@augusta.edu (I.A.S.); amanysinger77@gmail.com (A.M.M.A.-M.); \\ zakariaabdelsamii@yahoo.com (Z.K.M.A.-S.) \\ 3 Department of Chemistry \& Physics, Augusta University, Augusta, GA 30912, USA \\ 4 Department of Pharmaceutics, Faculty of Pharmacy, King Abdulaziz University, \\ Jeddah 21589, Saudi Arabia; nalhakamy@kau.edu.sa \\ 5 Department of Medical Microbiology and Parasitology, Faculty of Medicine, King Abdulaziz University, \\ Jeddah 21589, Saudi Arabia; hasfour@kau.edu.sa \\ 6 Department of Pharmaceutical Chemistry, faculty of pharmacy, Damanhour University, \\ Damanhour 22511, Egypt; alfath_tours@yahoo.com \\ * Correspondence: sipanda@augusta.edu; Tel.: +1-706-667-4022; Fax: +1-706-667-4519
}

Academic Editors: Ferenc Fulop and Dariusz Matosiuk

Received: 28 April 2020; Accepted: 26 May 2020; Published: 28 May 2020

check for updates

\begin{abstract}
A straightforward, mild and cost-efficient synthesis of various arylamides in water was accomplished using versatile benzotriazole chemistry. Acylation of various amines was achieved in water at room temperature as well as under microwave irradiation. The developed protocol unfolds the synthesis of amino acid aryl amides, drug conjugates and benzimidazoles. The environmentally friendly synthesis, short reaction time, simple workup, high yields, mild conditions and free of racemization are the key advantages of this protocol.
\end{abstract}

Keywords: green chemistry; one-pot synthesis; acylation; benzotriazole chemistry; benzimidazole; microwave; aryl amide

\section{Introduction}

$\mathrm{N}$-Acylation reactions are widely used in the organic chemistry, biology, pharmaceutical and agricultural industries [1-3]. Chemically, they are a straightforward and powerful tool for the protection of amino groups in multistep organic syntheses, for their convenient activation towards further chemical transformations, or as widespread amide building blocks in biologically active targets, natural products and pharmaceuticals $[4,5]$.

The amide bond is exceptionally imperative in medicinal chemistry [6-8]. Amide groups contribute to the unique properties of peptides, proteins, and numerous other natural and synthetic compounds. Most of the natural products and clinically used drugs contain an amide bond [9-14]. Approximately $25 \%$ of the pharmaceuticals present on the market contain at least one amide unit [15], and the functional group was present in $2 / 3$ of the drug candidates surveyed by three leading pharmaceutical companies in 2006 [16]. A survey of the literature reveals that many drugs available in the market, such as Penicillin (antibacterial), pyrazinamide (antitubercular), atorvastatin (antihyperlipidemic) [17] and valsartan (angiotensin receptor), possess their specific capabilities due to presence of amide linkage in their structures [18]. 
Acylation using acetyl chloride and acetic anhydride is common among various reported strategies. However, $\mathrm{N}$-acylation through acyl chloride and/or acid anhydride has been associated with many inherited disadvantages $[19,20]$. Further, for amino acid acylation, different coupling reagents are used, which are mostly nonselective, hazardous and difficult to handle [21].

To overcome the challenges of acyl chloride- and acid anhydride-mediated $N$-acylation reactions using acyl chlorides and/or acid anhydrides, numerous strategies have been investigated. Among them, the metal-catalyzed or direct coupling of unactivated carboxylic acids [22-24], acylation through $N$-acyl 1,5-diazabicyclo[4.3.0]non-5-ene (DBN) tetraphenylborate salts [25], Beckman rearrangements using mercury and ruthenium catalysts [26,27], copper-catalyzed oxidative amidation of aldehydes [28,29], triazole- and imidazole-mediated acyl transfer reactions [30-32], and acylation method through acylbenzotriazoles [33-35] are common. Benzotriazole chemistry has been explored, by the Katritzky group [19,21,36-40] and others [41,42], in various types of reactions, including in the synthesis of amides.

On the other hand, benzimidazoles are crucial core structures used to develop pharmaceuticals and materials. Substituted benzimidazoles exhibit biological activities such as antitumor [43], antihypertensive [44], antiulcer [45] and enzyme inhibition [46]. Some commonly employed synthetic methods for benzimidazoles include: (i) reaction of 1,2-phenylenediamines with carboxylic acids or their derivatives, like amidates, nitriles or orthoesters, in the presence of polyphosphoric acid [47] or mineral acids [48]; (ii) cyclization of $\mathrm{N}$-( $\mathrm{N}$-arylbenzimidoyl)-1,4-benzoquinoneimines under a thermal or acidic environment [49]; (iii) utilizing o-nitroanilines as intermediates [50]; (iv) oxidative cyclocondensation of o-phenylenediamine with aldehydes [51].

Recently, the development of green synthetic methods has become an important strategy in organic synthesis. Water has experienced increasing popularity due to being inexpensive, readily available, and environmentally benign. In addition, water: (i) is cheap, nonflammable, non-toxic and safe for use; (ii) eliminates additional efforts required to dry the substrates/reagents before use; (iii) offers unique physical and chemical properties that often achieve the reactivity or selectivity unattainable in organic solvents; and (iv) allows easy product isolation by filtration [52,53].

Benzotriazole chemistry has been practiced extensively in our group, and has often been found to be superior to conventional routes for acylation [21]. Earlier, we reported the acylation of mesalazine [54] and the synthesis of benzothiazole [52] in water under microwave conditions. In this communication, we extend the efficient synthetic protocol for the $\mathrm{N}$-acylation of amines, which could be an important tool for conjugate chemistry and also for the synthesis of 2-substituted benzimidazoles without any catalyst, organic solvent or additional reagent. This protocol runs under both microwave and room temperature and gives quantitative yields. To the best of our knowledge, this is the first environmentally benign, catalyst- and organic solvent-free synthesis of $\mathrm{N}$-acylated products of amines in water.

\section{Results and Discussion}

Carboxamines are important key intermediates, scaffolds for polymers, dendrimers and bioactive molecules [55]. Among arylamines, amino acid arylamides are often used as substrates in fluorogenic, chromogenic and amperogenic enzymatic assays [56]. For these applications, chirality is an important factor. Several methods have been reported for arylamides, including the use of enzymes and flow chemistry [57-71], and we believe we are reporting, for the first time, the synthesis of amino acid arylamides in water.

We investigated the reaction conditions for the $N$-acylation of anilines with our in-house prepared, protected aminoacylbenzotriazoles in water. Optimization of the reaction conditions showed the best outcomes under microwave irradiation at $50{ }^{\circ} \mathrm{C}$ for $15-20 \mathrm{~min}$, over conventional heating (Table 1). We were also able to get the desired product by stirring the reactants at room temperature for $1-2 \mathrm{~h}$. 
Table 1. Optimization of reaction condition.

\begin{tabular}{cccc}
\hline (1 equiv.) & Reaction Time & Yield a (\%) \\
\hline Entry & Reaction Temp. $\left({ }^{\circ} \mathrm{C}\right)$ & $\begin{array}{c}\text { no catalyst } \\
\text { or } \\
\text { no reagent }\end{array}$ \\
\hline 1 & 20 (Room temp.) & $2 \mathrm{~h}$ & 86 \\
\hline 2 & 20 (Room temp.) & $30 \mathrm{~min}$ & 77 \\
\hline 3 & 50 (Conv.) & $1 \mathrm{~h}$ & 82 \\
\hline 5 & 50 (Conv.) & $15 \mathrm{~min}$ & 96 \\
\hline 50 (MW) & &
\end{tabular}

There was no significant change in reaction time and yield when the above reaction was carried out both in tap water and saturated brine solution separately. Furthermore, we also tried the reaction in deionized water, to rule out the possibility of any metallic impurities from tap water catalyzing the reaction. The results obtained were comparable in tap and deionized water, so to avoid the effort and energy consumption needed to prepare deionized water, we chose tap water for our reactions.

Even though room temperature works for the $N$-acylation reactions, at a larger-scale, the reactions proceed nearly to completion as some of the reactants are left unreacted. We carried out the above reaction in both conventional heating and microwave irradiation conditions on a large scale. We got a better yield with high purity under microwave conditions, in comparison with conventional heating.

We therefore ran the reactions of aromatic amines with benzotriazolides of protected amino acids in water, under microwave irradiation for 15 to $20 \mathrm{~min}$ (Scheme 1). Our reaction condition yields pure $\mathrm{N}$-acylated products for all three types of protected amino acids (Boc, $\mathrm{Cbz}$ and Fmoc) with various substituted anilines (Table 2). We believe the driving force of the reaction is controlled by diffusion, since both of the reactants are water insoluble and form a heterogeneous reaction mixture. To justify our hypothesis, we used hexanes, a non-polar solvent, as a reaction medium in which both reactants are insoluble, and we found an equivalent outcome. We thus preferred nonflammable water over hexanes in our reactions. To explore the use of our reaction condition, we used different amines with various benzotriazolides. Our optimized reaction condition retains the chirality of the products, which was confirmed by performing reactions with both the DL and L forms of amino acids. High-performance liquid chromatography (HPLC) analysis of compound 9 (contains $L$-alanine) showed a single peak, with nearly the same retention time $(16.290 \mathrm{~min})$ as that of one of the two peaks (16.813 and $18.407 \mathrm{~min})$ obtained from the mixture of the racemic compound $9+9^{\prime}$ (contains $D L$-alanine) with the enantiopure compound 9 . The increase in height of one peak supports the retention of chiral integrity in our reaction protocol (Supplementary Material).

In addition to the primary amines, we also tried our optimized reaction condition with secondary amines. We were able to get the $N$-acylated secondary amines in good yields with high purity (Scheme 2). Earlier, we reported these conjugates, which were synthesized by treating benzotriazolide of boc-protected amino acids with secondary amines in the presence of triethylamine in tetrahydrofuran (THF) [35]. 


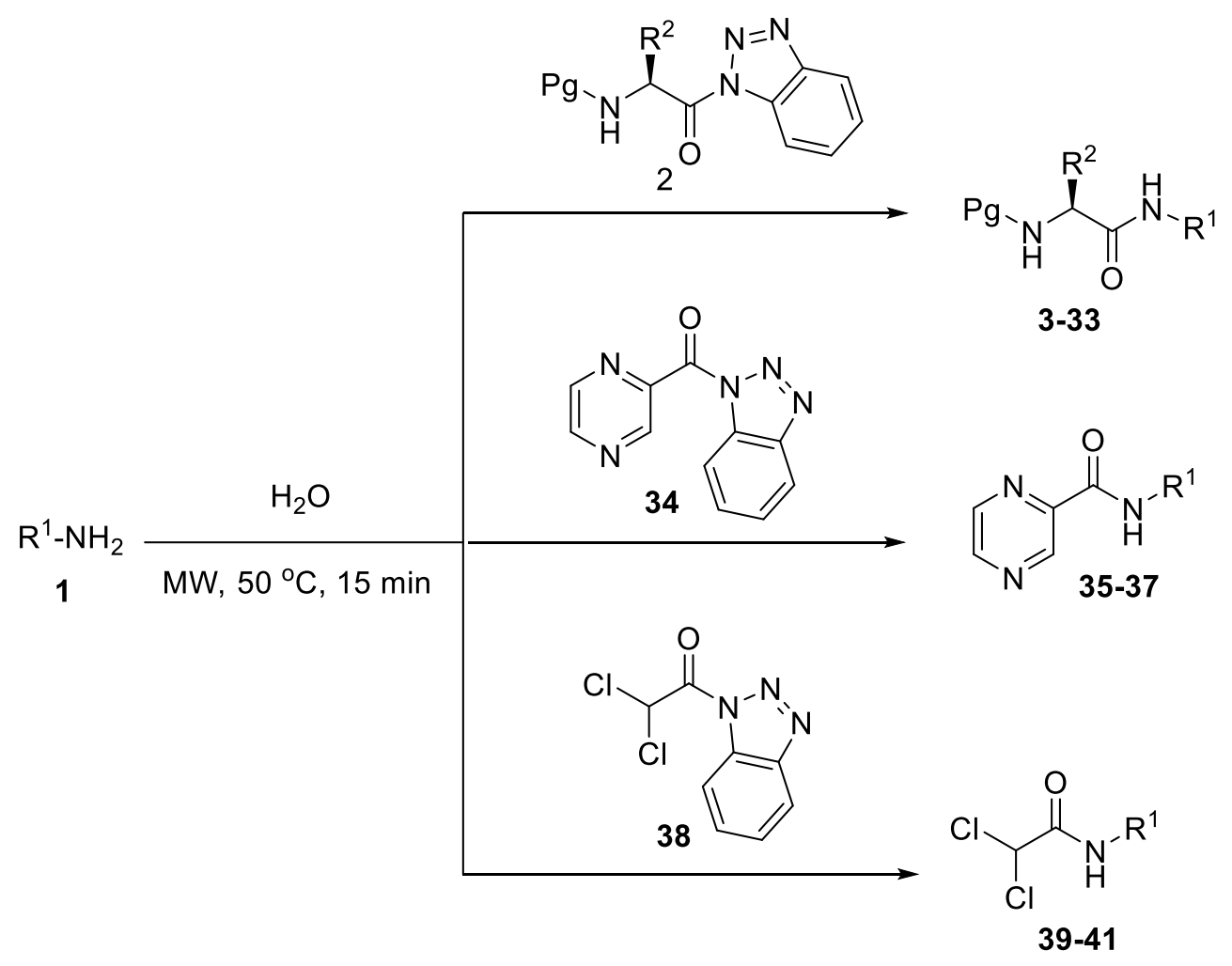

Scheme 1. Synthesis of $N$-acylated amines.

Table 2. Preparation of $N$-acylated amines.

Entry


Table 2. Cont.

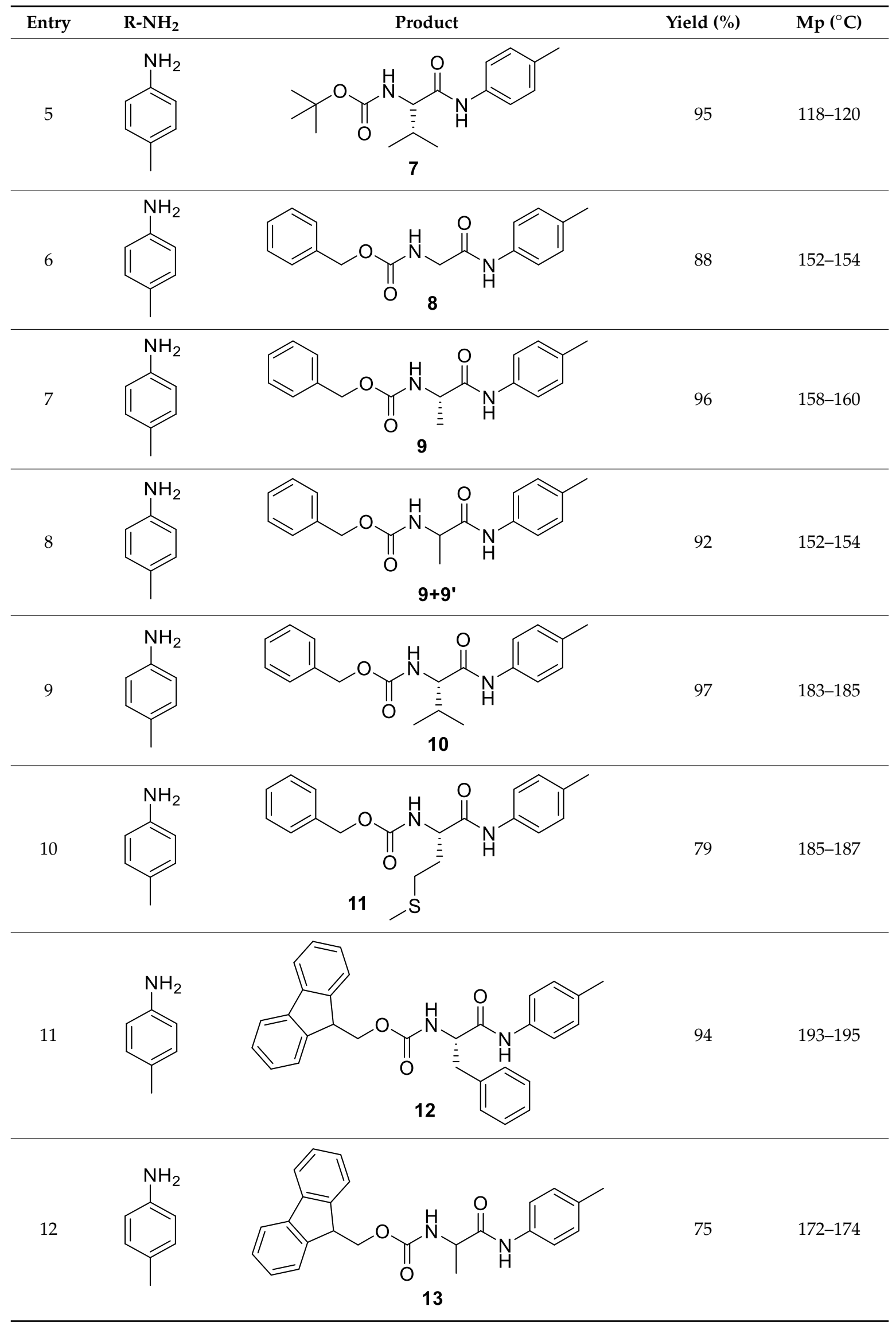


Table 2. Cont.

\begin{tabular}{|c|c|c|c|c|}
\hline Entry & $\mathrm{R}-\mathrm{NH}_{2}$ & Product & Yield (\%) & $\mathbf{M p}\left({ }^{\circ} \mathrm{C}\right)$ \\
\hline 13 & & & 80 & $164-166$ \\
\hline 14 & & & 85 & $160-162$ \\
\hline 15 & & & 98 & 185-187 \\
\hline 16 & & & 94 & $138-140$ \\
\hline 17 & & & 77 & 191-193 \\
\hline 18 & & & 84 & $174-176$ \\
\hline \multirow[t]{2}{*}{19} & & & 90 & 192-194 \\
\hline & $\mathrm{F}$ & 20 & & \\
\hline
\end{tabular}


Table 2. Cont.

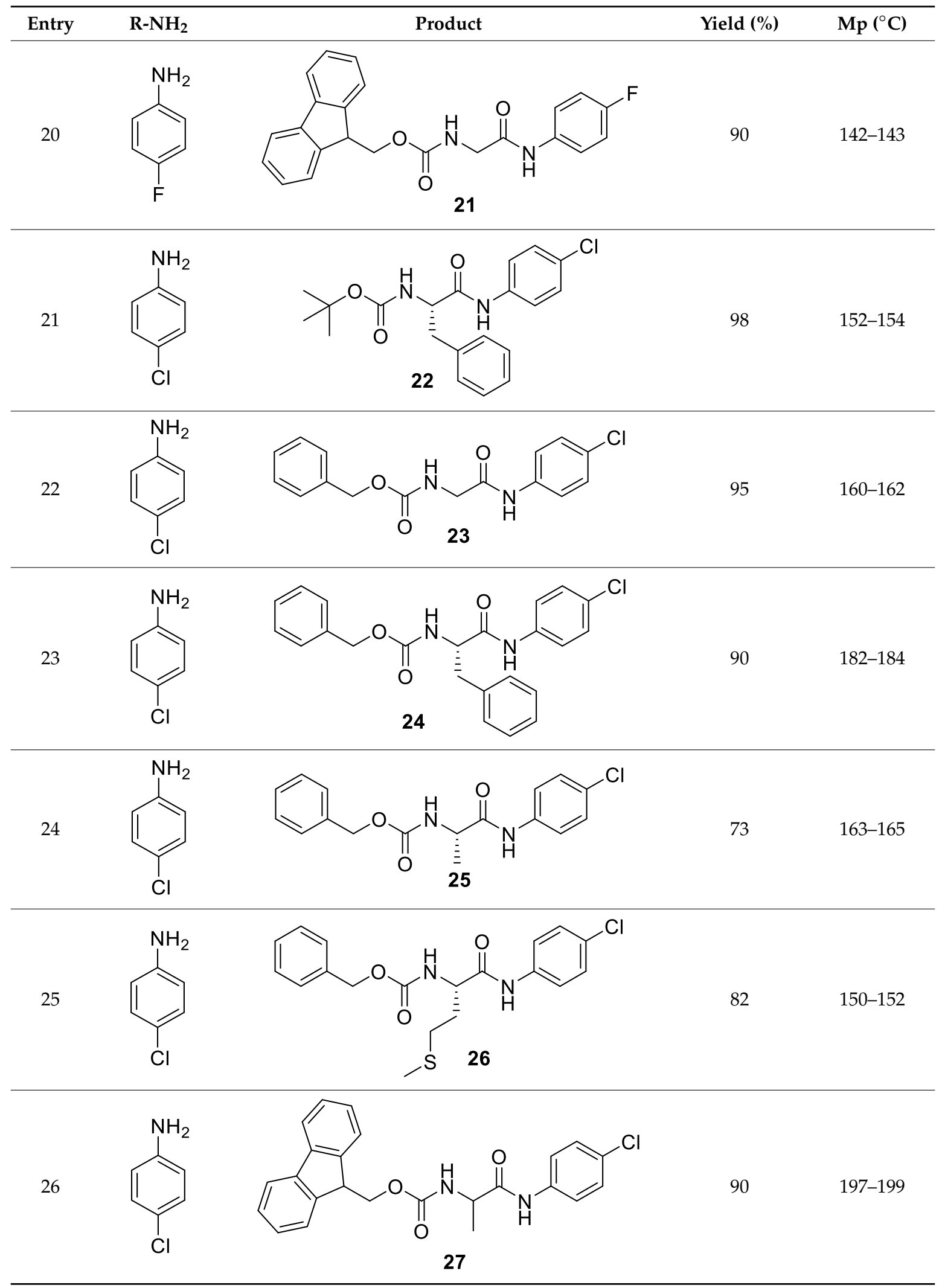


Table 2. Cont.

Entry Yield (\%)

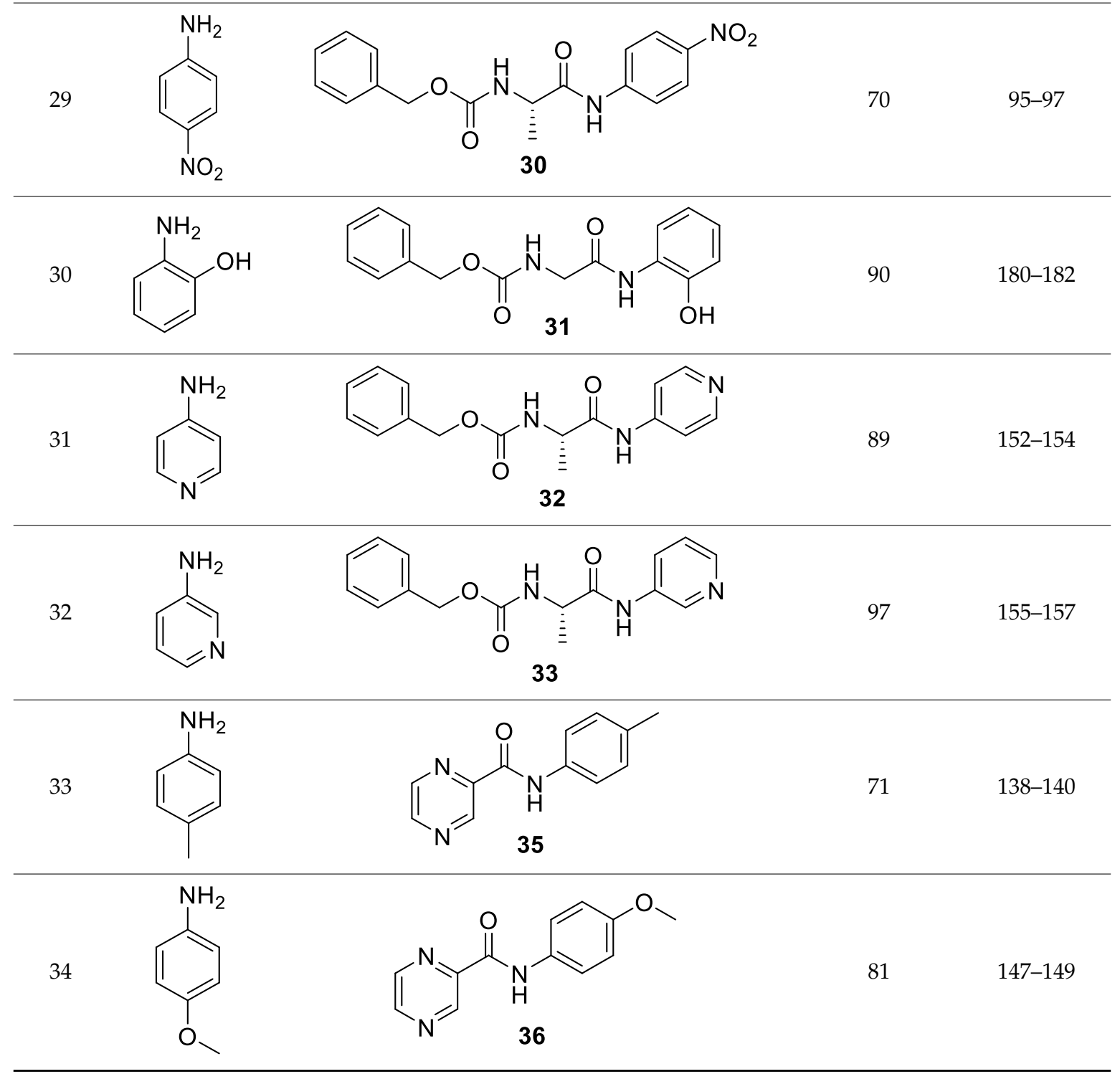


Table 2. Cont

Entry

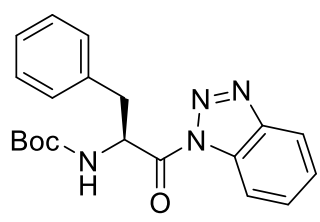

2

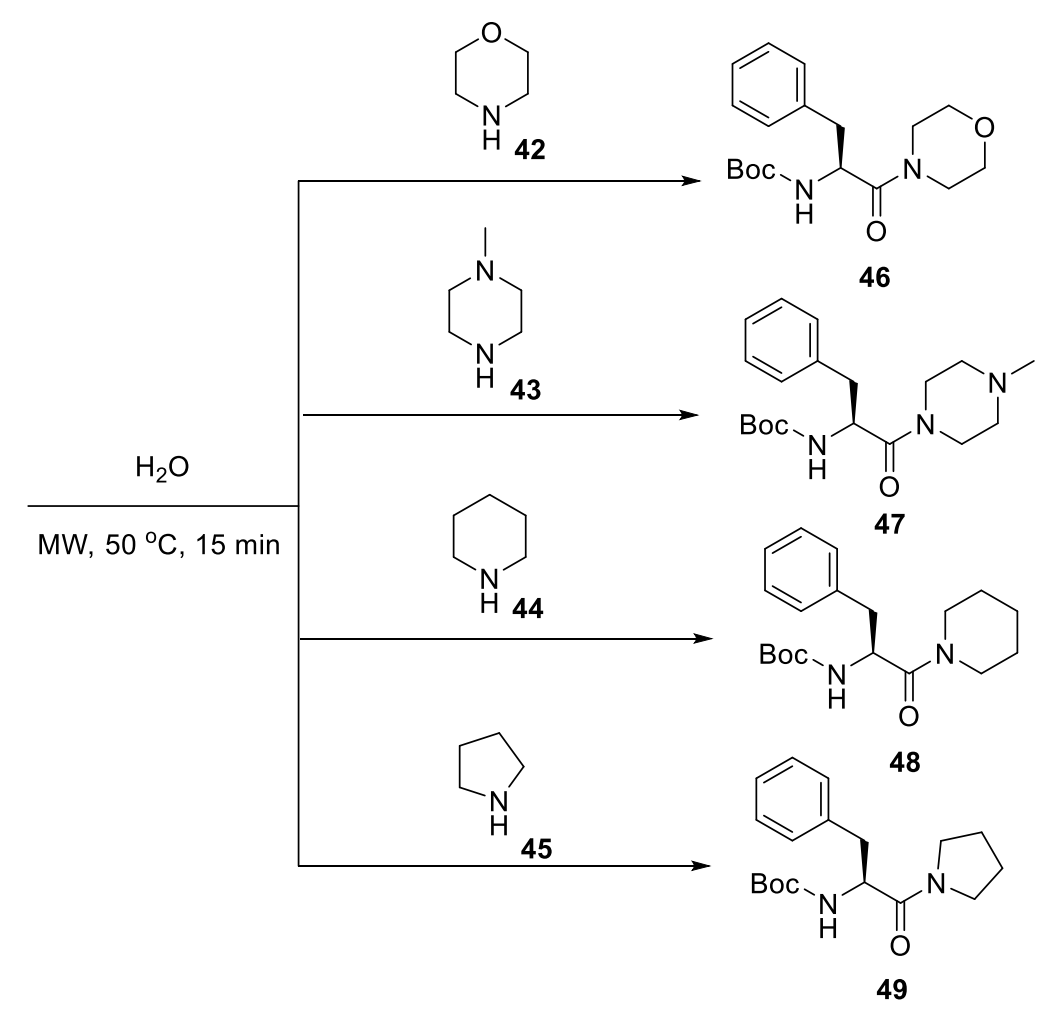

Scheme 2. Synthesis of Boc-protected amino acid with secondary heterocyclic amine conjugates. 
Despite tremendous success in the synthesis of 2-substituted benzimidazoles, many of the methodologies suffer from one or more limitations, such as long reaction times, the formation of several side products, harsh reaction conditions, low yields, complicated work-up procedures and the generation of acidic and metallic wastes. As a consequence, the development of a new method, or technical improvement of the existing methods, is still an important experimental challenge. To expand the range of applicability of our optimized greener protocol, we treated benzotriazole-activated substituted benzoic acids with o-phenylenediamine in water, under microwave conditions. We obtained our desired product in $1 \mathrm{~h}$ (Scheme 3).

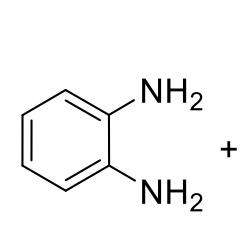

50<smiles>[R]c1ccc(C(=O)n2nnc3ccccc32)cc1</smiles>

51

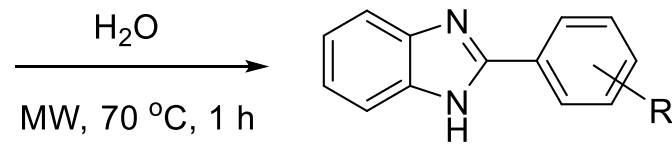

52-60<smiles>c1ccc(-c2nc3ccccc3[nH]2)cc1</smiles>

$52,82 \%$<smiles>Fc1ccc(-c2nc3ccccc3[nH]2)cc1</smiles>

53, $90 \%$<smiles>Clc1ccc(-c2nc3ccccc3[nH]2)cc1</smiles>

$54,88 \%$<smiles>Oc1ccc(-c2nc3ccccc3[nH]2)cc1</smiles>

55, $86 \%$<smiles>FC(F)(F)c1ccc(-c2nc3ccccc3[nH]2)cc1</smiles>

58, $83 \%$<smiles>O=[N+]([O-])c1ccc(-c2nc3ccccc3[nH]2)cc1</smiles>

56, $94 \%$<smiles>COc1ccc(-c2nc3ccccc3[nH]2)cc1</smiles>

$59,94 \%$<smiles>Cc1ccc(-c2nc3ccccc3[nH]2)cc1</smiles>

57, $92 \%$<smiles>COc1cc(-c2nc3ccccc3[nH]2)cc(OC)c1OC</smiles>

$60,92 \%$

Scheme 3. Synthesis of 2-substituted benzimidazoles.

To elucidate the use of water in our reaction protocol, we added $5 \mathrm{~mol} \%$ of a phase-transfer catalyst (Aliquat 336), which lowered the yields of the products, again supporting our proposed reaction mechanism of diffusion. The physical state of the reactants is also important: the use of microwave irradiation over conventional heating significantly improved the yields and purity, with retention of the chiral integrity. All the synthesized compounds were fully characterized by spectral studies (Supplementary Material).

\section{Conclusions}

In conclusion, we report mild, fast, efficient, facile and green conditions for the $\mathrm{N}$-acylation of amines in water, without the use of catalyst or reagent. The heterogeneous reaction runs in water and forms the $\mathrm{N}$-acylated products without loss of chirality and with high yields. The optimized reaction conditions 
work well at room temperature as well as under microwave irradiation for small-scale reactions, but for large-scale reactions microwave conditions are preferred. The application of microwaves and the concept of a heterogeneous reaction mixture expands the use of the reaction condition for the synthesis of 2-substituted benzimidazoles. Given its qualities of being racemization-free, high yield, catalyst- and solvent-free and ecofriendly, as well as the possibility of it scaling-up, the reaction has substantial potential for implementation by the pharmaceutical and agriculture industries.

\section{Experimental Section}

Melting points were determined on a capillary point apparatus equipped with a digital thermometer. NMR spectra were recorded in $\left(\mathrm{DMSO}-\mathrm{d}_{6}\right)$ on Bruker NMR spectrometers operating at $500 \mathrm{MHz}$ for $1 \mathrm{H}$ [with tetramethysilane (TMS) as an internal standard] and $125 \mathrm{MHz}$ for 13C. All microwave-assisted reactions were carried out with a single mode cavity Discover Microwave Synthesizer (CEM Corporation, Charlotte, NC, USA). The reaction mixtures were transferred into a $10 \mathrm{~mL}$ glass pressure microwave tube equipped with a magnetic stirrer bar. The tube was closed with a silicon septum and the reaction mixture was subjected to microwave irradiation (Discover mode; run time: 60 s; Power Max-cooling mode). HPLC analysis was carried out on Agilent 6120 LCMS instrument with Chirobiotic T column.

\subsection{General Methods for N-acylation}

In a typical procedure, a mixture of amine (1 equiv.) and N-protected aminoacylbenzotriazole or arylylbenzotriazole (1 equiv.) was subjected to microwave irradiation $\left(20 \mathrm{~W}, 50{ }^{\circ} \mathrm{C}\right)$ in water $(3 \mathrm{~mL})$ for 15-20 min. After completion of the reaction, aqueous $\mathrm{Na}_{2} \mathrm{CO}_{3}$ or $4 \mathrm{~N} \mathrm{HCl}$ was added and the mixture was extracted with ethyl acetate or filter the precipitates, followed by washing with water. In most of the cases the isolated products were in pure form, and some were recrystallized in ethanol. Benzotriazoles could be recovered from the aqueous layer by $\mathrm{pH}$-controlled acidification.

tert-Butyl (S)-(1-oxo-3-phenyl-1-(phenylamino)propan-2-yl)carbamate (3). White microcrystals (94\%); m.p. $137-139{ }^{\circ} \mathrm{C}$ (Lit. m.p. $138-139{ }^{\circ} \mathrm{C}$ [57]). ${ }^{1} \mathrm{H}$ NMR (500 MHz, DMSO-d 6 ) $\delta: 10.01$ (s, $\left.1 \mathrm{H}\right), 7.58$ $(\mathrm{d}, J=7.8 \mathrm{~Hz}, 1 \mathrm{H}), 7.44-6.90(\mathrm{~m}, 10 \mathrm{H}), 4.32(\mathrm{~s}, 1 \mathrm{H}), 3.49-1.79(\mathrm{~m}, 2 \mathrm{H}), 2.01-0.59(\mathrm{~m}, 9 \mathrm{H}) .{ }^{13} \mathrm{C} \mathrm{NMR}$ $\left(125 \mathrm{MHz}, \mathrm{DMSO}-d_{6}\right) \delta: 171.2,155.9,139.4,138.4,129.9,129.7,129.6,129.3,129.2,128.6,128.5,126.7$, $126.7,123.8,119.9,119.8,78.6,57.0,37.9,28.6$. HRMS $m / z$ calcd for $\mathrm{C}_{20} \mathrm{H}_{24} \mathrm{~N}_{2} \mathrm{O}_{3}[\mathrm{M}+\mathrm{H}]^{+} 341.1787$, found 341.1789 .

tert-Butyl (S)-(3-methyl-1-oxo-1-(phenylamino)butan-2-yl)carbamate (4). White microcrystals (93\%); m.p. 123-125 ${ }^{\circ} \mathrm{C}$ (Lit. m.p. 120-121 $\left.{ }^{\circ} \mathrm{C}[58]\right) .{ }^{1} \mathrm{H}$ NMR (500 MHz, DMSO-d 6 ) $\delta 9.95(\mathrm{~s}, 1 \mathrm{H}), 7.60(\mathrm{~d}, J=7.4 \mathrm{~Hz}$, $2 \mathrm{H}), 7.30(\mathrm{t}, J=7.2 \mathrm{~Hz}, 2 \mathrm{H}), 7.05(\mathrm{t}, J=7.5 \mathrm{~Hz}, 1 \mathrm{H}), 6.82(\mathrm{~d}, J=6.7 \mathrm{~Hz}, 1 \mathrm{H}), 3.94(\mathrm{t}, J=8.6 \mathrm{~Hz}, 1 \mathrm{H})$, 2.06-1.94 (m, 1H), 1.39 (s, 9H), $0.90(\mathrm{~d}, J=5.1 \mathrm{~Hz}, 6 \mathrm{H}) ;{ }^{13} \mathrm{C}$ NMR $\left(125 \mathrm{MHz}\right.$, DMSO- $\left.d_{6}\right) \delta 171.2,156.1,139.3$, $129.2,123.8,119.7,78.5,61.0,30.9,28.7,19.7$. HRMS $m / z$ calcd for $\mathrm{C}_{16} \mathrm{H}_{24} \mathrm{~N}_{2} \mathrm{O}_{3}[\mathrm{M}+\mathrm{H}]^{+} 293.1787$, found 293.1786.

Benzyl (2-oxo-2-(phenylamino)ethyl)carbamate (5). White microcrystals (95\%); m.p. $145-146{ }^{\circ} \mathrm{C}$ (Lit. m.p. $\left.148-149{ }^{\circ} \mathrm{C}[59]\right) .{ }^{1} \mathrm{H}$ NMR (500 MHz, DMSO-d 6$) \delta 9.99(\mathrm{~s}, 1 \mathrm{H}), 7.61(\mathrm{~d}, J=7.6 \mathrm{~Hz}, 2 \mathrm{H})$, $7.55(\mathrm{t}, J=6.8 \mathrm{~Hz}, 1 \mathrm{H}), 7.43-7.23(\mathrm{~m}, 7 \mathrm{H}), 7.05(\mathrm{t}, J=6.8 \mathrm{~Hz}, 1 \mathrm{H}), 5.07(\mathrm{~s}, 2 \mathrm{H}), 3.84(\mathrm{~d}, J=5.7 \mathrm{~Hz}, 2 \mathrm{H})$; ${ }^{13} \mathrm{C}$ NMR $(125 \mathrm{MHz}$, DMSO-d 6 ) $\delta 168.4,157.1,139.4,137.5,129.2,128.8,128.3,128.2,123.7,119.6,66.0$, 44.6. HRMS $m / z$ calcd for $\mathrm{C}_{16} \mathrm{H}_{16} \mathrm{~N}_{2} \mathrm{O}_{3}[\mathrm{M}+\mathrm{H}]^{+} 285.1161$, found 285.1169 .

(9H-Fluoren-9-yl)methyl (2-oxo-2-(phenylamino)ethyl)carbamate (6). White microcrystals (91\%); m.p. 165-167 ${ }^{\circ} \mathrm{C}$ [60]. ${ }^{1} \mathrm{H}$ NMR (500 MHz, DMSO-d $) \delta 10.02(\mathrm{~s}, 1 \mathrm{H}), 7.89(\mathrm{~d}, J=7.4 \mathrm{~Hz}, 2 \mathrm{H}), 7.74$ $(\mathrm{d}, J=7.3 \mathrm{~Hz}, 2 \mathrm{H}), 7.66-7.58(\mathrm{~m}, 3 \mathrm{H}), 7.42(\mathrm{t}, J=7.2 \mathrm{~Hz}, 2 \mathrm{H}), 7.36-7.29(\mathrm{~m}, 4 \mathrm{H}), 7.05(\mathrm{t}, J=6.4 \mathrm{~Hz}, 1 \mathrm{H})$, $4.33(\mathrm{~d}, J=6.7 \mathrm{~Hz}, 2 \mathrm{H}), 4.25(\mathrm{t}, J=6.5 \mathrm{~Hz}, 1 \mathrm{H}), 3.84(\mathrm{~d}, J=5.7 \mathrm{~Hz}, 2 \mathrm{H}) . ;{ }^{13} \mathrm{C} \mathrm{NMR}\left(125 \mathrm{MHz}, \mathrm{DMSO}-d_{6}\right)$ $\delta 168.4,157.1,144.3,141.2,139.4,129.9,129.2,128.1,127.6,125.7,123.7,120.6,119.6,66.2,47.1,44.5$. HRMS $m / z$ calcd for $\mathrm{C}_{23} \mathrm{H}_{20} \mathrm{~N}_{2} \mathrm{O}_{3}[\mathrm{M}+\mathrm{H}]^{+} 373.1474$, found 373.1477 .

tert-Butyl (R)-(3-methyl-1-oxo-1-(p-tolylamino)butan-2-yl)carbamate (7). Yellow microcrystals (95\%); m.p. $118-120{ }^{\circ} \mathrm{C}$ (Lit. m.p. $\left.115-117{ }^{\circ} \mathrm{C}[58]\right) .{ }^{1} \mathrm{H}$ NMR (500 MHz, DMSO-d 6$) \delta 9.05$ (s, $\left.1 \mathrm{H}\right), 7.39$ $(\mathrm{d}, J=7.6 \mathrm{~Hz}, 2 \mathrm{H}), 6.99(\mathrm{~d}, J=5.0 \mathrm{~Hz}, 2 \mathrm{H}), 5.79(\mathrm{~d}, J=9.2 \mathrm{~Hz}, 1 \mathrm{H}), 4.25(\mathrm{t}, J=7.9 \mathrm{~Hz}, 1 \mathrm{H}), 2.28(\mathrm{~s}, 3 \mathrm{H})$, 
2.21-2.13 (m, 1H), $1.43(\mathrm{~s}, 9 \mathrm{H}), 1.05(\mathrm{~d}, J=7.1 \mathrm{~Hz}, 6 \mathrm{H}) ;{ }^{13} \mathrm{C}$ NMR $\left(125 \mathrm{MHz}, \mathrm{DMSO}-d_{6}\right) \delta 170.8,156.6$, $135.4,133.5,129.2,120.2,80.0,60.8,31.3,28.4,20.8,19.3$. HRMS $m / z$ calcd for $\mathrm{C}_{17} \mathrm{H}_{26} \mathrm{~N}_{2} \mathrm{O}_{3}[\mathrm{M}+\mathrm{H}]^{+}$ 307.1943, found 307.1944.

Benzyl (2-oxo-2-(p-tolylamino)ethyl)carbamate (8). White microcrystals (88\%); m.p. $152-154{ }^{\circ} \mathrm{C}$ (Lit. m.p. 153-154 $\left.{ }^{\circ} \mathrm{C}[61]\right) .{ }^{1} \mathrm{H}$ NMR $\left(500 \mathrm{MHz}, \mathrm{DMSO}-d_{6}\right) \delta: 9.86(\mathrm{~s}, 1 \mathrm{H}), 7.52(\mathrm{t}, J=5.8 \mathrm{~Hz}, 1 \mathrm{H}), 7.46(\mathrm{~d}, J=8.2 \mathrm{~Hz}$, $1 \mathrm{H}), 7.40-7.29(\mathrm{~m}, 6 \mathrm{H}), 7.10(\mathrm{~d}, J=8.2 \mathrm{~Hz}, 2 \mathrm{H}), 5.05(\mathrm{~s}, 2 \mathrm{H}), 3.79(\mathrm{~d}, J=6.1 \mathrm{~Hz}, 2 \mathrm{H}), 2.24(\mathrm{~s}, 3 \mathrm{H}) .{ }^{13} \mathrm{C} \mathrm{NMR}$ (125 MHz, DMSO-d 6 ) $\delta:$ 167.6, 156.6, 137.0, 136.4, 132.1, 129.1, 128.4, 128.3, 128.2, 127.9, 127.8, 127.7, 126.4, 119.1, 65.5, 43.9, 20.4. HRMS $m / z$ calcd for $\mathrm{C}_{17} \mathrm{H}_{18} \mathrm{~N}_{2} \mathrm{O}_{3}[\mathrm{M}+\mathrm{H}]^{+} 299.1317$, found 299.1319.

Benzyl (S)-(1-oxo-1-(p-tolylamino) propan-2-yl) carbamate (9). White microcrystals (96\%); m.p. 158-160 ${ }^{\circ} \mathrm{C}$ (Lit. m.p. $\left.160-162{ }^{\circ} \mathrm{C}[59]\right) .{ }^{1} \mathrm{H}$ NMR (500 MHz, DMSO-d $\left.d_{6}\right) \delta: 9.86(\mathrm{~s}, 1 \mathrm{H}), 7.56(\mathrm{~d}, J=7.2 \mathrm{~Hz}, 1 \mathrm{H})$, $7.47(\mathrm{~d}, J=8.0 \mathrm{~Hz}, 1 \mathrm{H}), 7.41-7.24(\mathrm{~m}, 6 \mathrm{H}), 7.10(\mathrm{~d}, J=8.1 \mathrm{~Hz}, 2 \mathrm{H}), 5.02(\mathrm{q}, J=12.6 \mathrm{~Hz}, 2 \mathrm{H}), 4.37-3.96$ $(\mathrm{m}, 1 \mathrm{H}), 2.25(\mathrm{~s}, 3 \mathrm{H}), 1.28(\mathrm{~d}, J=7.1 \mathrm{~Hz}, 3 \mathrm{H}) .{ }^{13} \mathrm{C}$ NMR $\left(125 \mathrm{MHz}, \mathrm{DMSO}-d_{6}\right) \delta: 171.2,155.7,136.9,136.5$, 132.1, 129.0, 129.0, 128.4, 128.3, 127.8, 127.7, 127.5, 119.2, 118.4, 65.4, 50.7, 20.4, 18.1. HRMS $\mathrm{m} / \mathrm{z}$ calcd for $\mathrm{C}_{18} \mathrm{H}_{20} \mathrm{~N}_{2} \mathrm{O}_{3}[\mathrm{M}+\mathrm{H}]^{+}$313.1474, found 313.1481.

Benzyl (RS)-(1-oxo-1-(p-tolylamino) propan-2-yl) carbamate (9+9'). White solid (92\%), m.p. $152-154{ }^{\circ} \mathrm{C}$. 1H NMR (500 MHz, DMSO-d6) 8: $9.86(\mathrm{~s}, 1 \mathrm{H}), 7.56(\mathrm{~s}, 1 \mathrm{H}), 7.47$ (d, J = 8.0 Hz, 2H), 7.39-7.26 (m, 5H), $7.10(\mathrm{~d}, \mathrm{~J}=8.2 \mathrm{~Hz}, 2 \mathrm{H}), 5.02(\mathrm{q}, \mathrm{J}=12.6 \mathrm{~Hz}, 2 \mathrm{H}), 4.34-4.01(\mathrm{~m}, 1 \mathrm{H}), 2.25(\mathrm{~s}, 3 \mathrm{H}), 1.28(\mathrm{~d}, \mathrm{~J}=7.1 \mathrm{~Hz}$,

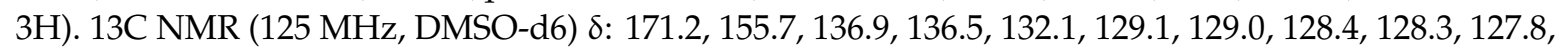
127.8, 127.7, 119.2, 119.2, 65.3, 50.7, 20.4, 18.1. HRMS m/z calcd for C18H20N2O3 [M + H]+ 313.1474, found 313.1488.

Benzyl (S)-(3-methyl-1-oxo-1-(p-tolylamino)butan-2-yl)carbamate (10). White microcrystals (97\%); m.p. $183-185^{\circ} \mathrm{C}[62] .{ }^{1} \mathrm{H}$ NMR $\left(500 \mathrm{MHz}\right.$, DMSO- $\left.d_{6}\right) \delta 9.98(\mathrm{~s}, 1 \mathrm{H}), 7.60-7.25(\mathrm{~m}, 8 \mathrm{H}), 7.15(\mathrm{~d}, J=6.4 \mathrm{~Hz}$, $2 \mathrm{H}), 5.09(\mathrm{~s}, 2 \mathrm{H}), 4.03(\mathrm{t}, J=6.4 \mathrm{~Hz}, 1 \mathrm{H}), 2.29(\mathrm{~s}, 3 \mathrm{H}), 2.15-1.94(\mathrm{~m}, 1 \mathrm{H}), 0.95(\mathrm{~d}, J=3.9 \mathrm{~Hz}, 6 \mathrm{H}) ;{ }^{13} \mathrm{C} \mathrm{NMR}$ $\left(125 \mathrm{MHz}\right.$, DMSO- $\left.d_{6}\right) \delta 170.7,156.8,137.5,136.8,132.8,129.6,128.9,128.3,128.2,119.8,66.0,61.5,30.9$, 20.9, 19.7. HRMS $m / z$ calcd for $\mathrm{C}_{20} \mathrm{H}_{24} \mathrm{~N}_{2} \mathrm{O}_{3}[\mathrm{M}+\mathrm{H}]^{+} 341.1787$, found 341.1788.

Benzyl (S)-(4-(methylthio)-1-oxo-1-(p-tolylamino)butan-2-yl)carbamate (11). White microcrystals (79\%); m.p. $185-187^{\circ} \mathrm{C} .{ }^{1} \mathrm{H}$ NMR $\left(500 \mathrm{MHz}, \mathrm{DMSO}-\mathrm{d}_{6}\right) \delta: 9.94(\mathrm{~s}, 1 \mathrm{H}), 7.63(\mathrm{~d}, J=7.8 \mathrm{~Hz}, 1 \mathrm{H}), 7.48(\mathrm{~d}, J=8.2$ $\mathrm{Hz}, 2 \mathrm{H}), 7.42-7.25(\mathrm{~m}, 5 \mathrm{H}), 7.11(\mathrm{~d}, J=8.2 \mathrm{~Hz}, 2 \mathrm{H}), 5.07-4.99(\mathrm{~m}, 2 \mathrm{H}), 4.22(\mathrm{dd}, J=13.2,8.5 \mathrm{~Hz}, 1 \mathrm{H})$, 2.66-2.32 (m, 2H), 2.25 (s, 3H), $2.04(\mathrm{~s}, 3 \mathrm{H}), 2.05-1.69(\mathrm{~m}, 2 \mathrm{H}) .{ }^{13} \mathrm{C}$ NMR (125 MHz, DMSO-d $\left.d_{6}\right) \delta: 170.2$, 156.1, 136.9, 136.3, 132.2, 129.1, 129.0, 128.3, 128.3, 127.8, 127.8, 127.7, 119.3, 119.3, 65.4, 54.6, 31.6, 29.7, 20.4, 14.6. HRMS $m / z$ calcd for $\mathrm{C}_{20} \mathrm{H}_{24} \mathrm{~N}_{2} \mathrm{O}_{3} \mathrm{~S}[\mathrm{M}+\mathrm{H}]^{+} 372.1508$, found 372.1512.

(9H-Fluoren-9-yl)methyl(S)-(1-oxo-3-phenyl-1-(p-tolylamino)propan-2-yl)carbamate (12). White microcrystals (94\%); m.p. 193-195 ${ }^{\circ} \mathrm{C} .{ }^{1} \mathrm{H}$ NMR (500 MHz, DMSO- $\left.d_{6}\right) \delta 10.03(\mathrm{~s}, 1 \mathrm{H}), 7.86(\mathrm{~d}, J=7.3 \mathrm{~Hz}, 2 \mathrm{H}), 7.73(\mathrm{~d}$, $J=8.3 \mathrm{~Hz}, 1 \mathrm{H}), 7.64(\mathrm{t}, J=7.5 \mathrm{~Hz}, 2 \mathrm{H}), 7.47(\mathrm{~d}, J=7.8 \mathrm{~Hz}, 2 \mathrm{H}), 7.42-7.24(\mathrm{~m}, 9 \mathrm{H}), 7.11(\mathrm{~d}, J=7.7 \mathrm{~Hz}$, $2 \mathrm{H}), 4.48-4.35(\mathrm{~m}, 1 \mathrm{H}), 4.23-4.14(\mathrm{~m}, 3 \mathrm{H}), 3.08-3.00(\mathrm{~m}, 1 \mathrm{H}), 2.96-2.84(\mathrm{~m}, 1 \mathrm{H}), 2.24(\mathrm{~s}, 3 \mathrm{H}) ;{ }^{13} \mathrm{C}$ NMR $\left(125 \mathrm{MHz}, \mathrm{DMSO}-d_{6}\right) \delta 170.7,156.4,144.1,141.1,138.3,136.7,133.0,129.7,129.6,128.6,128.1,127.5$, $126.9,125.7,120.5,119.9,66.2,57.3,47.0,38.0,20.9$. HRMS $m / z$ calcd for $\mathrm{C}_{31} \mathrm{H}_{28} \mathrm{~N}_{2} \mathrm{O}_{3}[\mathrm{M}+\mathrm{H}]^{+} 477.2100$, found 477.2109 .

(9H-Fluoren-9-yl)methyl (1-oxo-1-(p-tolylamino)propan-2-yl)carbamate (13). White microcrystals (75\%); m.p. $172-174{ }^{\circ} \mathrm{C} .{ }^{1} \mathrm{H}$ NMR $\left(500 \mathrm{MHz}, \mathrm{DMSO}-d_{6}\right) \delta: 9.87(\mathrm{~s}, 1 \mathrm{H}), 7.89(\mathrm{~d}, J=7.5 \mathrm{~Hz}, 2 \mathrm{H}), 7.76-7.54$ $(\mathrm{m}, 3 \mathrm{H}), 7.51-7.43(\mathrm{~m}, 2 \mathrm{H}), 7.44-7.29(\mathrm{~m}, 4 \mathrm{H}), 7.10(\mathrm{~d}, J=8.2 \mathrm{~Hz}, 2 \mathrm{H}), 4.39-4.09(\mathrm{~m}, 4 \mathrm{H}), 2.25(\mathrm{~s}, 3 \mathrm{H})$, 1.43-1.21 (m, 3H). ${ }^{13} \mathrm{C}$ NMR (125 MHz, DMSO- $\left.d_{6}\right) \delta: 171.3,155.8,143.9,140.7,136.5,132.1,129.0,127.6$, 127.0, 125.3, 120.1, 119.1, 65.6, 50.7, 46.6, 20.4, 18.1. HRMS $m / z$ calcd for $\mathrm{C}_{25} \mathrm{H}_{24} \mathrm{~N}_{2} \mathrm{O}_{3}[\mathrm{M}+\mathrm{H}]^{+} 401.1787$, found 401.1785 .

Benzyl (S)-(1-((4-methoxyphenyl)amino)-1-oxo-3-phenylpropan-2-yl)carbamate (14). White microcrystals (80\%); m.p. $164-166{ }^{\circ} \mathrm{C}$ [Lit. m.p. $167{ }^{\circ} \mathrm{C}$ [63]]. ${ }^{1} \mathrm{H}$ NMR (500 MHz, DMSO-d 6 ) $\delta: 9.94(\mathrm{~s}, 1 \mathrm{H}), 7.64$ $(\mathrm{d}, J=8.4 \mathrm{~Hz}, 1 \mathrm{H}), 7.48(\mathrm{~d}, J=8.9 \mathrm{~Hz}, 2 \mathrm{H}), 7.36-7.20(\mathrm{~m}, 10 \mathrm{H}), 6.88(\mathrm{~d}, J=9.0 \mathrm{~Hz}, 2 \mathrm{H}), 4.96(\mathrm{~s}, 2 \mathrm{H}), 4.38$ $(\mathrm{td}, J=9.7,4.8 \mathrm{~Hz}, 1 \mathrm{H}), 3.72(\mathrm{~s}, 3 \mathrm{H}), 3.02(\mathrm{dd}, J=13.6,4.6 \mathrm{~Hz}, 1 \mathrm{H}), 2.85(\mathrm{dd}, J=15.5,8.2 \mathrm{~Hz}, 1 \mathrm{H}) .{ }^{13} \mathrm{C} \mathrm{NMR}$ $\left(125 \mathrm{MHz}\right.$, DMSO-d $\left.d_{6}\right) \delta:$ 169.9, 155.9, 155.3, 137.9, 136.9, 131.9, 129.8, 129.21, 129.1, 128.3, 128.2, 128.0, 127.7, 
127.5, 127.4, 126.5, 126.3, 124.9, $120.9,113.8,65.3,56.8,55.1,37.6$. HRMS $m / z$ calcd for $\mathrm{C}_{24} \mathrm{H}_{24} \mathrm{~N}_{2} \mathrm{O}_{4}[\mathrm{M}+\mathrm{H}]^{+}$ 405.1736, found 405.1737 .

Benzyl (S)-(1-((4-methoxyphenyl)amino)-1-oxopropan-2-yl)carbamate (15). White microcrystals (85\%); m.p. $160-162{ }^{\circ} \mathrm{C}$ (Lit. m.p. $\left.161.5-162.5{ }^{\circ} \mathrm{C}[64]\right) .{ }^{1} \mathrm{H}$ NMR $\left(500 \mathrm{MHz}\right.$, DMSO- $\left.d_{6}\right) \delta: 9.88(\mathrm{~s}, 1 \mathrm{H}), 7.63-7.45$ $(\mathrm{m}, 3 \mathrm{H}), 7.42-7.27(\mathrm{~m}, 5 \mathrm{H}), 6.88(\mathrm{~d}, J=9.0 \mathrm{~Hz}, 2 \mathrm{H}), 5.03(\mathrm{q}, J=12.6 \mathrm{~Hz}, 2 \mathrm{H}), 4.35-4.04(\mathrm{~m}, 1 \mathrm{H}), 3.72$ $(\mathrm{s}, 3 \mathrm{H}), 1.29(\mathrm{~d}, J=7.1 \mathrm{~Hz}, 3 \mathrm{H}) .{ }^{13} \mathrm{C}$ NMR $\left(125 \mathrm{MHz}, \mathrm{DMSO}-d_{6}\right) \delta: 171.0,155.7,154.8,137.0,132.2$, 132.1, 128.4, 128.3, 127.8, 127.7, 125.4, 125.3, 120.7, 113.8, 65.4, 55.2, 50.7, 18.2. HRMS m/z calcd for $\mathrm{C}_{18} \mathrm{H}_{20} \mathrm{~N}_{2} \mathrm{O}_{4}[\mathrm{M}+\mathrm{H}]^{+}$329.1423, found 329.1431.

Benzyl (S)-(1-((2-methoxyphenyl)amino)-1-oxopropan-2-yl)carbamate (16). White microcrystals (98\%); m.p. $185-187{ }^{\circ} \mathrm{C}[65] .{ }^{1} \mathrm{H}$ NMR $\left(500 \mathrm{MHz}, \mathrm{DMSO}-d_{6}\right) \delta: 9.04(\mathrm{~s}, 1 \mathrm{H}), 8.03(\mathrm{~d}, J=7.4 \mathrm{~Hz}, 1 \mathrm{H}), 7.75$ $(\mathrm{d}, J=6.7 \mathrm{~Hz}, 1 \mathrm{H}), 7.47-7.21(\mathrm{~m}, 5 \mathrm{H}), 7.16-6.97(\mathrm{~m}, 2 \mathrm{H}), 6.91(\mathrm{t}, J=8.2 \mathrm{~Hz}, 1 \mathrm{H}), 5.06(\mathrm{q}, J=12.4 \mathrm{~Hz}$, 2H), 4.45-4.18 (m, $1 \mathrm{H}), 3.81(\mathrm{~s}, 3 \mathrm{H}), 1.29(\mathrm{~d}, J=7.1 \mathrm{~Hz}, 3 \mathrm{H}) .{ }^{13} \mathrm{C}$ NMR $\left(125 \mathrm{MHz}, \mathrm{DMSO}-d_{6}\right) \delta: 171.3$, 155.9, 148.9, 136.9, 128.4, 128.4, 127.8, 127.7, 127.1, 124.2, 124.2, 120.6, 120.3, 111.1, 65.5, 55.8, 50.9, 17.8. HRMS $m / z$ calcd for $\mathrm{C}_{18} \mathrm{H}_{20} \mathrm{~N}_{2} \mathrm{O}_{4}[\mathrm{M}+\mathrm{H}]^{+} 329.1423$, found 329.1422 .

tert-Butyl (S)-(1-((4-fluorophenyl)amino)-3-methyl-1-oxobutan-2-yl)carbamate (17). Yellow microcrystals (94\%); m.p. $138-140{ }^{\circ} \mathrm{C}$ (Lit. m.p. $141-142{ }^{\circ} \mathrm{C}[58]$ ). ${ }^{1} \mathrm{H}$ NMR $\left(500 \mathrm{MHz}, \mathrm{DMSO}-d_{6}\right) \delta 10.02(\mathrm{~s}, 1 \mathrm{H}), 7.62$ $(\mathrm{dd}, J=7.9,5.1 \mathrm{~Hz}, 2 \mathrm{H}), 7.13(\mathrm{t}, J=8.7 \mathrm{~Hz}, 2 \mathrm{H}), 6.83(\mathrm{~d}, J=8.2 \mathrm{~Hz}, 1 \mathrm{H}), 3.91(\mathrm{t}, J=7.6 \mathrm{~Hz}, 1 \mathrm{H}), 2.04-1.94$ $(\mathrm{m}, 1 \mathrm{H}), 1.39(\mathrm{~s}, 9 \mathrm{H}), 0.90(\mathrm{~d}, J=6.3 \mathrm{~Hz}, 6 \mathrm{H}) ;{ }^{13} \mathrm{C}$ NMR (125 MHz, DMSO- $\left.d_{6}\right) \delta 171.1,159.4,157.5,156.1$, $135.7,121.5,121.4,115.8,115.6,78.5,61.0,30.8,28.6,19.6$. HRMS $m / z$ calcd for $\mathrm{C}_{16} \mathrm{H}_{23} \mathrm{FN}_{2} \mathrm{O}_{3}[\mathrm{M}+\mathrm{H}]^{+}$ 311.1693, found 311.1699.

Benzyl (S)-(1-((4-fluorophenyl) amino)-1-oxo-3-phenylpropan-2-yl) carbamate (18). White microcrystals

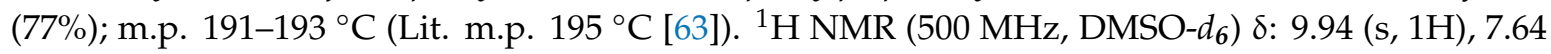
$(\mathrm{d}, J=8.4 \mathrm{~Hz}, 1 \mathrm{H}), 7.48(\mathrm{~d}, J=8.9 \mathrm{~Hz}, 2 \mathrm{H}), 7.36-7.20(\mathrm{~m}, 10 \mathrm{H}), 6.88(\mathrm{~d}, J=9.0 \mathrm{~Hz}, 2 \mathrm{H}), 4.96(\mathrm{~s}, 2 \mathrm{H})$, $4.38(\mathrm{td}, J=9.7,4.8 \mathrm{~Hz}, 1 \mathrm{H}), 3.72(\mathrm{~s}, 3 \mathrm{H}), 3.02(\mathrm{dd}, J=13.6,4.6 \mathrm{~Hz}, 1 \mathrm{H}), 2.85(\mathrm{dd}, J=15.5,8.2 \mathrm{~Hz}, 1 \mathrm{H})$. ${ }^{13} \mathrm{C}$ NMR (125 MHz, DMSO- $\left.d_{6}\right) \delta: 169.9,155.9,155.3,137.9,136.9,131.9,129.8,129.21,129.1,128.3$, 128.2, 128.0, 127.7, 127.5, 127.4, 126.5, 126.3, 124.9, 120.9, 113.8, 65.3, 56.8, 55.1, 37.6. HRMS $m / z$ calcd for $\mathrm{C}_{23} \mathrm{H}_{21} \mathrm{FN}_{2} \mathrm{O}_{3}[\mathrm{M}+\mathrm{H}]^{+}$393.1536, found 393.1533.

Benzyl (2-((4-fluorophenyl)amino)-2-oxoethyl)carbamate (19). White microcrystals (84\%); m.p. $174-176{ }^{\circ} \mathrm{C}$. ${ }^{1} \mathrm{H}$ NMR $\left(500 \mathrm{MHz}\right.$, DMSO- $\left.d_{6}\right) \delta: 10.02(\mathrm{~s}, 1 \mathrm{H}), 7.61(\mathrm{dd}, J=8.8,5.0 \mathrm{~Hz}, 2 \mathrm{H}), 7.56(\mathrm{t}, J=6.0 \mathrm{~Hz}, 1 \mathrm{H})$, 7.41-7.32 (m, 6H), $7.15(\mathrm{t}, J=8.9 \mathrm{~Hz}, 1 \mathrm{H}), 5.06(\mathrm{~s}, 2 \mathrm{H}), 3.80(\mathrm{~d}, J=6.1 \mathrm{~Hz}, 2 \mathrm{H}) .{ }^{13} \mathrm{C}$ NMR $(125 \mathrm{MHz}$, DMSO- $d_{6}$ ) $\delta: 167.8,158.9,156.6,137.0,135.3,128.4,128.3,128.2,127.8,127.7,120.8,120.8,115.4,115.2,65.5$, 43.9. HRMS $m / z$ calcd for $\mathrm{C}_{16} \mathrm{H}_{15} \mathrm{FN}_{2} \mathrm{O}_{3}[\mathrm{M}+\mathrm{H}]^{+}$303.1067, found 303.1066.

Benzyl (S)-(1-((4-fluorophenyl)amino)-1-oxopropan-2-yl)carbamate (20). White microcrystals (90\%); m.p. $192-194{ }^{\circ} \mathrm{C}[65] .{ }^{1} \mathrm{H}$ NMR $\left(500 \mathrm{MHz}, \mathrm{DMSO}-d_{6}\right) \delta: 10.03(\mathrm{~s}, 1 \mathrm{H}), 7.69-7.51(\mathrm{~m}, 3 \mathrm{H}), 7.44-7.25$ $(\mathrm{m}, 5 \mathrm{H}), 7.23-7.04(\mathrm{~m}, 2 \mathrm{H}), 5.03(\mathrm{q}, J=12.7 \mathrm{~Hz}, 2 \mathrm{H}), 4.32-3.96(\mathrm{~m}, 1 \mathrm{H}), 1.29(\mathrm{~d}, J=7.1 \mathrm{~Hz}, 3 \mathrm{H}) .{ }^{13} \mathrm{C} \mathrm{NMR}$ (125 MHz, DMSO-d $\left.d_{6}\right) \delta: 171.4,158.9,155.8,136.9,135.4,128.3,128.30,127.8,127.71,127.7,120.9,120.9$, 115.3, 115.1, 65.4, 50.7, 17.9. HRMS $m / z$ calcd for $\mathrm{C}_{17} \mathrm{H}_{17} \mathrm{FN}_{2} \mathrm{O}_{3}[\mathrm{M}+\mathrm{H}]^{+} 317.1223$, found 317.1228.

(9H-Fluoren-9-yl)methyl (2-((4-fluorophenyl)amino)-2-oxoethyl)carbamate (21). Yellow microcrystals (90\%); m.p. $142-143{ }^{\circ} \mathrm{C} .{ }^{1} \mathrm{H}$ NMR $\left(500 \mathrm{MHz}, \mathrm{DMSO}-d_{6}\right) \delta 10.20(\mathrm{~s}, 1 \mathrm{H}), 7.66(\mathrm{~d}, J=8.0 \mathrm{~Hz}, 1 \mathrm{H})$, $7.64-7.54(\mathrm{~m}, 2 \mathrm{H}), 7.36-7.19(\mathrm{~m}, 10 \mathrm{H}), 7.15(\mathrm{t}, J=8.4 \mathrm{~Hz}, 2 \mathrm{H}), 4.97(\mathrm{~s}, 2 \mathrm{H}), 4.45-4.36(\mathrm{~m}, 1 \mathrm{H}), 3.07-3.00$ (m, 1H), 2.90-2.82 (m, 1H); ${ }^{13} \mathrm{C}$ NMR $\left(125 \mathrm{MHz}\right.$, DMSO- $\left.d_{6}\right) \delta 170.9,159.6,157.6,156.5,138.1,137.4$, 135.6, 129.7, 128.8, 128.6, 128.2, 128.0, 126.9, 121.7, 121.7, 115.8, 115.7, 65.8, 57.4, 37.9. HRMS m/z calcd for $\mathrm{C}_{23} \mathrm{H}_{19} \mathrm{FN}_{2} \mathrm{O}_{3}[\mathrm{M}+\mathrm{H}]^{+}$391.1380, found 391.1393.

tert-Butyl (S)-(1-((4-chlorophenyl)amino)-1-oxo-3-phenylpropan-2-yl)carbamate (22). White microcrystals (98\%); m.p. ${ }^{152-154}{ }^{\circ} \mathrm{C}[66] . ~{ }^{1} \mathrm{H}$ NMR (500 MHz, DMSO- $\left.d_{6}\right) \delta: 10.17(\mathrm{~s}, 1 \mathrm{H}), 7.61(\mathrm{~d}, J=8.8 \mathrm{~Hz}, 2 \mathrm{H})$, 7.50-7.00 (m, 8H), $4.31(\mathrm{dd}, J=12.8,9.2 \mathrm{~Hz}, 1 \mathrm{H}), 3.26-2.65(\mathrm{~m}, 2 \mathrm{H}), 1.59-1.11(\mathrm{~m}, 9 \mathrm{H}) .{ }^{13} \mathrm{C}$ NMR $(125 \mathrm{MHz}$, DMSO- $d_{6}$ ) $\delta: 170.9,155.4,138.0,137.8,129.3,129.2,129.0,128.8,128.6,128.1,128.0,126.8,126.3,126.3,120.8$, 78.1, 56.6, 55.1, 37.3, 28.1. HRMS $m / z$ calcd for $\mathrm{C}_{20} \mathrm{H}_{23} \mathrm{ClN}_{2} \mathrm{O}_{3}[\mathrm{M}+\mathrm{H}]^{+} 375.1397$, found 375.1389.

Benzyl (2-((4-chlorophenyl)amino)-2-oxoethyl)carbamate (23). White microcrystals (95\%); m.p. $160-162{ }^{\circ} \mathrm{C}$. ${ }^{1} \mathrm{H}$ NMR (500 MHz, DMSO-d $\left.)_{6}\right) \delta: 10.10(\mathrm{~s}, 1 \mathrm{H}), 7.62(\mathrm{~d}, J=8.7 \mathrm{~Hz}, 2 \mathrm{H}), 7.56(\mathrm{t}, J=5.9 \mathrm{~Hz}, 1 \mathrm{H}), 7.42-7.29$ 
$(\mathrm{m}, 7 \mathrm{H}), 5.05(\mathrm{~s}, 2 \mathrm{H}), 3.81(\mathrm{~d}, J=6.1 \mathrm{~Hz}, 2 \mathrm{H}) .{ }^{13} \mathrm{C}$ NMR $\left(125 \mathrm{MHz}, \mathrm{DMSO}-d_{6}\right) \delta: 168.6,157.1,138.3$, $137.5,131.5,129.1,128.9,128.8,128.7,128.3,128.2,127.2,127.1,121.1,65.9,44.6$. HRMS $\mathrm{m} / \mathrm{z}$ calcd for $\mathrm{C}_{16} \mathrm{H}_{15} \mathrm{ClN}_{2} \mathrm{O}_{3}[\mathrm{M}+\mathrm{H}]^{+}$319.0771, found 319.0777.

Benzyl (S)-(1-((4-chlorophenyl)amino)-1-oxo-3-phenylpropan-2-yl)carbamate (24). White microcrystal (90\%); m.p. $182-184{ }^{\circ} \mathrm{C} .{ }^{1} \mathrm{H}$ NMR $\left(500 \mathrm{MHz}, \mathrm{DMSO}-d_{6}\right) \delta: 10.29(\mathrm{~s}, 1 \mathrm{H}), 7.76(\mathrm{~d}, J=7.8 \mathrm{~Hz}, 1 \mathrm{H}), 7.63$ $(\mathrm{d}, J=8.8 \mathrm{~Hz}, 2 \mathrm{H}), 7.44-7.23(\mathrm{~m}, 11 \mathrm{H}), 7.21(\mathrm{~d}, J=7.2 \mathrm{~Hz}, 1 \mathrm{H}), 4.96(\mathrm{~s}, 2 \mathrm{H}), 4.80-3.81(\mathrm{~m}, 1 \mathrm{H}), 3.02$ $(\mathrm{dd}, J=13.7,4.6 \mathrm{~Hz}, 1 \mathrm{H}), 2.86(\mathrm{dd}, J=13.6,10.3 \mathrm{~Hz}, 1 \mathrm{H}) .{ }^{13} \mathrm{C}$ NMR $\left(125 \mathrm{MHz}\right.$, DMSO- $\left.d_{6}\right) \delta: 171.2,156.4$, 138.3, 138.2, 137.4, 130.0, 129.8, 129.7, 129.1, 128.8, 128.8, 128.7, 128.6, 128.2, 128.0, 127.8, 127.4, 127.3, $126.9,121.3,65.8,57.5,37.9$. HRMS $m / z$ calcd for $\mathrm{C}_{23} \mathrm{H}_{21} \mathrm{ClN}_{2} \mathrm{O}_{3}[\mathrm{M}+\mathrm{H}]^{+}$409.1241, found 409.1244.

Benzyl (S)-(1-((4-chlorophenyl)amino)-1-oxopropan-2-yl)carbamate (25). White microcrystal (73\%); m.p. $163-165{ }^{\circ} \mathrm{C}$ (Lit. m.p. $\left.165-166{ }^{\circ} \mathrm{C}[67]\right) .{ }^{1} \mathrm{H}$ NMR $\left(500 \mathrm{MHz}\right.$, DMSO- $\left.d_{6}\right) \delta: 10.11$ (s, 1H), 7.72-7.55 $(\mathrm{m}, 3 \mathrm{H}), 7.42-7.28(\mathrm{~m}, 7 \mathrm{H}), 5.53-4.69(\mathrm{~m}, 2 \mathrm{H}), 4.50-3.73(\mathrm{~m}, 1 \mathrm{H}), 1.29(\mathrm{~d}, J=7.1 \mathrm{~Hz}, 3 \mathrm{H}) .{ }^{13} \mathrm{C} \mathrm{NMR}$ $\left(125 \mathrm{MHz}\right.$, DMSO-d $\left.d_{6}\right) \delta: 171.7,155.78,137.9,136.9,128.6,128.6,128.3,128.3,127.8,127.7,126.8,126.7$, 120.8, 120.7, 65.4, 50.8, 17.9. HRMS $m / z$ calcd for $\mathrm{C}_{17} \mathrm{H}_{17} \mathrm{ClN}_{2} \mathrm{O}_{3}[\mathrm{M}+\mathrm{H}]^{+} 333.0928$, found 333.0923.

Benzyl (S)-(1-((4-chlorophenyl)amino)-4-(methylthio)-1-oxobutan-2-yl)carbamate (26). White microcrystal (82\%); m.p. 150-152 ${ }^{\circ} \mathrm{C}[68] .{ }^{1} \mathrm{H}$ NMR (500 MHz, DMSO- $\left.d_{6}\right) \delta: 10.20(\mathrm{~s}, 1 \mathrm{H}), 8.28-7.57(\mathrm{~m}, 3 \mathrm{H}), 7.47-7.27$ $(\mathrm{m}, 7 \mathrm{H}), 5.11-4.97(\mathrm{~m}, 2 \mathrm{H}), 4.24(\mathrm{dd}, J=12.9,8.5 \mathrm{~Hz}, 1 \mathrm{H}), 2.84-2.29(\mathrm{~m}, 2 \mathrm{H}), 2.06(\mathrm{~s}, 3 \mathrm{H}), 1.98-1.82(\mathrm{~m}, 2 \mathrm{H})$. ${ }^{13} \mathrm{C}$ NMR $\left(125 \mathrm{MHz}\right.$, DMSO- $\left.d_{6}\right) \delta: 170.7,156.1,137.8,136.9,131.7,128.6,128.3,128.3,127.8,127.7,127.7$ $126.9,120.9,119.7,65.5,54.7,31.4,29.7,14.6$. HRMS $m / z$ calcd for $\mathrm{C}_{19} \mathrm{H}_{21} \mathrm{ClN}_{2} \mathrm{O}_{3} \mathrm{~S}[\mathrm{M}+\mathrm{H}]^{+} 393.0961$, found 393.0969 .

(9H-Fluoren-9-yl)methyl (1-((4-chlorophenyl)amino)-1-oxopropan-2-yl)carbamate (27). White microcrystal (90\%); m.p. $197-199^{\circ} \mathrm{C} .{ }^{1} \mathrm{H}$ NMR (500 MHz, DMSO-d $\left.d_{6}\right) \delta: 10.13(\mathrm{~s}, 1 \mathrm{H}), 7.89(\mathrm{~d}, J=7.4 \mathrm{~Hz}, 2 \mathrm{H}), 7.82-7.54$ $(\mathrm{m}, 5 \mathrm{H}), 7.48-7.25(\mathrm{~m}, 6 \mathrm{H}), 4.65-3.89(\mathrm{~m}, 4 \mathrm{H}), 1.30(\mathrm{~d}, J=7.1 \mathrm{~Hz}, 3 \mathrm{H}) .{ }^{13} \mathrm{C}$ NMR $\left(125 \mathrm{MHz}\right.$, DMSO- $\left.d_{6}\right) \delta$ : 171.7, 155.8, 143.8, 143.8, 140.7, 137.9, 128.6, 127.6, 127.0, 126.7, 125.3, 125.3, 125.2, 120.7, 120.1, 65.6, 50.8, 46.6, 17.9. HRMS $m / z$ calcd for $\mathrm{C}_{24} \mathrm{H}_{21} \mathrm{ClN}_{2} \mathrm{O}_{3}[\mathrm{M}+\mathrm{H}]^{+} 421.1241$, found 421.1235 .

(9H-Fluoren-9-yl)methyl (S)-(1-((4-chlorophenyl)amino)-1-oxo-3-phenylpropan-2-yl)carbamate (28). White microcrystal; (98\%); m.p. $210-212{ }^{\circ} \mathrm{C} .{ }^{1} \mathrm{H}$ NMR $\left(500 \mathrm{MHz}, \mathrm{DMSO}-d_{6}\right) \delta: 7.92-7.80(\mathrm{~m}, 4 \mathrm{H})$, $7.75-7.59(\mathrm{~m}, 2 \mathrm{H}), 7.41(\mathrm{dd}, J=11.1,4.6 \mathrm{~Hz}, 3 \mathrm{H}), 7.37-7.02(\mathrm{~m}, 10 \mathrm{H}), 6.27(\mathrm{~s}, 1 \mathrm{H}), 4.64-3.86(\mathrm{~m}, 3 \mathrm{H})$, 3.48-2.68 (m, 2H). ${ }^{13} \mathrm{C}$ NMR (125 MHz, DMSO- $\left.d_{6}\right) \delta: 172.2,143.9,142.6,139.40,137.4,135.4,133.2,129.5$, $129.4,129.2,128.9,128.5,128.0,127.8,127.3,126.1,125.7,123.9,122.3,122.2,121.4,121.2,120.7,120.0$, 115.3, 109.7, 79.2, 57.2, 53.8, 37.9. HRMS $m / z$ calcd for $\mathrm{C}_{30} \mathrm{H}_{25} \mathrm{ClN}_{2} \mathrm{O}_{3}[\mathrm{M}+\mathrm{H}]^{+}$497.1554, found 497.1553.

Benzyl (S)-(1-((2-chlorophenyl)amino)-1-oxopropan-2-yl)carbamate (29). White microcrystal (70\%); m.p. $162-164^{\circ} \mathrm{C} .{ }^{1} \mathrm{H}$ NMR $\left(500 \mathrm{MHz}\right.$, DMSO- $\left.d_{6}\right) \delta: 9.43(\mathrm{~s}, 1 \mathrm{H}), 7.76(\mathrm{~d}, J=7.8 \mathrm{~Hz}, 1 \mathrm{H}), 7.70(\mathrm{~d}, J=6.8 \mathrm{~Hz}$, $1 \mathrm{H}), 7.49(\mathrm{~d}, J=7.9 \mathrm{~Hz}, 1 \mathrm{H}), 7.42-7.28(\mathrm{~m}, 6 \mathrm{H}), 7.19(\mathrm{t}, J=7.5 \mathrm{~Hz}, 1 \mathrm{H}), 5.05(\mathrm{~s}, 2 \mathrm{H}), 4.45-4.14(\mathrm{~m}, 1 \mathrm{H})$, $1.33(\mathrm{~d}, J=7.1 \mathrm{~Hz}, 3 \mathrm{H}) .{ }^{13} \mathrm{C}$ NMR $\left(125 \mathrm{MHz}, \mathrm{DMSO}-d_{6}\right) \delta: 171.72,155.9,136.9,134.56,129.4,129.4$, $128.3,128.3,127.8,127.7,127.5,126.2,126.0,125.3,65.5,50.6,17.8$. HRMS $m / z$ calcd for $\mathrm{C}_{17} \mathrm{H}_{17} \mathrm{ClN}_{2} \mathrm{O}_{3}$ $[\mathrm{M}+\mathrm{H}]^{+}$333.0928, found 333.0941.

Benzyl (S)-(1-((4-nitrophenyl)amino)-1-oxopropan-2-yl)carbamate (30). White microcrystal (70\%); m.p. 95-97 ${ }^{\circ} \mathrm{C}$ (Lit. m.p. $\left.99{ }^{\circ} \mathrm{C}[69]\right) .{ }^{1} \mathrm{H}$ NMR $\left(500 \mathrm{MHz}, \mathrm{DMSO}-d_{6}\right) \delta: 8.93-8.01(\mathrm{~m}, 3 \mathrm{H}), 7.82(\mathrm{t}, J=7.6 \mathrm{~Hz}$, $1 \mathrm{H}), 7.65(\mathrm{t}, J=7.7 \mathrm{~Hz}, 1 \mathrm{H}), 7.54-7.20(\mathrm{~m}, 4 \mathrm{H}), 7.16-6.81(\mathrm{~m}, 1 \mathrm{H}), 5.59-5.38(\mathrm{~m}, 1 \mathrm{H}), 5.12-4.95(\mathrm{~m}, 2 \mathrm{H})$, $1.54(\mathrm{~d}, J=7.2 \mathrm{~Hz}, 3 \mathrm{H}) .{ }^{13} \mathrm{C}$ NMR $\left(125 \mathrm{MHz}, \mathrm{DMSO}-d_{6}\right) \delta: 172.4,156.0,145.3,136.7,131.2,130.7,128.4$, $128.3,127.9,127.8,127.7,126.8,120.2,113.9,65.8,50.1,16.8$. HRMS $m / z$ calcd for $\mathrm{C}_{17} \mathrm{H}_{17} \mathrm{~N}_{3} \mathrm{O}_{5}[\mathrm{M}+\mathrm{H}]^{+}$ 344.1168, found 344.1160 .

Benzyl (2-((2-hydroxyphenyl)amino)-2-oxoethyl)carbamate (31). White microcrystals (90\%); m.p. $180-182^{\circ} \mathrm{C}$ (Lit. m.p. 174-176 $\left.{ }^{\circ} \mathrm{C}[65]\right) .1 \mathrm{H} \mathrm{NMR}\left(500 \mathrm{MHz}\right.$, DMSO-d $\left.d_{6}\right) \delta 9.93(\mathrm{~s}, 1 \mathrm{H}), 9.11(\mathrm{~s}, 1 \mathrm{H}), 7.98-7.83(\mathrm{~m}, 1 \mathrm{H})$, 7.82-7.64 (m, 1H), 7.52-7.23 (m, 5H), 6.98-6.73 (m, 2H), $5.08(\mathrm{~s}, 2 \mathrm{H}), 3.88(\mathrm{~d}, J=4.7 \mathrm{~Hz}, 2 \mathrm{H}) ;{ }^{13} \mathrm{C} \mathrm{NMR}$ (125 MHz, DMSO- $\left.d_{6}\right) \delta 168.6,157.2,147.7,137.4,128.9,128.3,128.1,126.5,124.8,121.6,119.5,115.7,66.1,44.9$. HRMS $m / z$ calcd for $\mathrm{C}_{16} \mathrm{H}_{16} \mathrm{~N}_{2} \mathrm{O}_{4}[\mathrm{M}+\mathrm{H}]^{+} 301.1110$, found 301.1117 .

Benzyl (S)-(1-oxo-1-(pyridin-4-ylamino)propan-2-yl)carbamate (32). White microcrystals (89\%); m.p. 152-154 ${ }^{\circ} \mathrm{C}$ [70]. ${ }^{1} \mathrm{H}$ NMR (500 MHz, DMSO- $\left.d_{6}\right) \delta: 8.43-8.14(\mathrm{~m}, 4 \mathrm{H}), 7.82(\mathrm{t}, J=7.7 \mathrm{~Hz}, 1 \mathrm{H}), 7.65$ 
$(\mathrm{t}, J=7.7 \mathrm{~Hz}, 1 \mathrm{H}), 7.47-7.22(\mathrm{~m}, 5 \mathrm{H}), 5.51-5.49(\mathrm{~m}, 1 \mathrm{H}), 5.07-5.02(\mathrm{~m}, 2 \mathrm{H}), 1.54(\mathrm{~d}, J=7.2 \mathrm{~Hz}, 3 \mathrm{H})$. ${ }^{13} \mathrm{C}$ NMR $\left(125 \mathrm{MHz}\right.$, DMSO-d $\left.d_{6}\right) \delta: 172.4,156.0,145.3,136.7,131.1,130.6,128.4,128.3,127.9,127.8,126.7$, 120.2, 113.9, 65.8, 50.1, 16.8. HRMS $m / z$ calcd for $\mathrm{C}_{16} \mathrm{H}_{17} \mathrm{~N}_{3} \mathrm{O}_{3}[\mathrm{M}+\mathrm{H}]^{+} 300.1270$, found 300.1274.

Benzyl (S)-(1-oxo-1-(pyridin-3-ylamino)propan-2-yl)carbamate (33). White microcrystals (97\%); m.p. $155-157^{\circ} \mathrm{C} .{ }^{1} \mathrm{H}$ NMR $\left(500 \mathrm{MHz}, \mathrm{DMSO}-d_{6}\right) \delta: 8.39-8.13(\mathrm{~m}, 4 \mathrm{H}), 7.82(\mathrm{t}, J=7.7 \mathrm{~Hz}, 1 \mathrm{H}), 7.65$ $(\mathrm{t}, J=7.7 \mathrm{~Hz}, 1 \mathrm{H}), 7.46-7.24(\mathrm{~m}, 5 \mathrm{H}), 5.53-5.47(\mathrm{~m}, 1 \mathrm{H}), 5.07-5.02(\mathrm{~m}, 2 \mathrm{H}), 1.54(\mathrm{~d}, J=7.3 \mathrm{~Hz}, 3 \mathrm{H})$. ${ }^{13} \mathrm{C}$ NMR $\left(125 \mathrm{MHz}\right.$, DMSO- $\left.d_{6}\right) \delta: 172.4,156.0,145.3,137.0,136.7,131.1,130.6,128.4,127.9,127.8,126.8$, 120.2, 113.9, 65.8, 50.1, 16.8. HRMS $m / z$ calcd for $\mathrm{C}_{16} \mathrm{H}_{17} \mathrm{~N}_{3} \mathrm{O}_{3}[\mathrm{M}+\mathrm{H}]^{+} 300.1270$, found 300.1265.

$\mathrm{N}$-(p-Tolyl)pyrazine-2-carboxamide (35). White microcrystals (71\%); m.p. $138-140^{\circ} \mathrm{C}$ (Lit. m.p. $148^{\circ} \mathrm{C}$ [72]). ${ }^{1} \mathrm{H}$ NMR $\left(500 \mathrm{MHz}, \mathrm{DMSO}-d_{6}\right) \delta: 10.62(\mathrm{~s}, 1 \mathrm{H}), 9.28(\mathrm{~d}, J=1.4 \mathrm{~Hz}, 1 \mathrm{H}), 8.92(\mathrm{~d}, J=2.5 \mathrm{~Hz}, 1 \mathrm{H}), 8.80(\mathrm{dd}$, $J=2.5,1.4 \mathrm{~Hz}, 1 \mathrm{H}), 7.77(\mathrm{~d}, J=8.4 \mathrm{~Hz}, 2 \mathrm{H}), 7.17(\mathrm{~d}, J=8.3 \mathrm{~Hz}, 2 \mathrm{H}), 2.29(\mathrm{~s}, 3 \mathrm{H}) .{ }^{13} \mathrm{C} \mathrm{NMR}(125 \mathrm{MHz}$, DMSO- $\left.d_{6}\right) \delta: 161.4,147.6,145.1,143.9,143.2,135.6,133.2,129.04,120.5,20.5$. HRMS $m / z$ calcd for $\mathrm{C}_{12} \mathrm{H}_{11} \mathrm{~N}_{3} \mathrm{O}$ $[\mathrm{M}+\mathrm{H}]^{+}$214.0902, found 214.0913.

$\mathrm{N}$-(4-Methoxyphenyl)pyrazine-2-carboxamide (36). White microcrystals (81\%); m.p. $147-149{ }^{\circ} \mathrm{C}$ (Lit. m.p. $\left.149-150{ }^{\circ} \mathrm{C}[73]\right) .{ }^{1} \mathrm{H}$ NMR $\left(500 \mathrm{MHz}, \mathrm{DMSO}-d_{6}\right) \delta: 10.62(\mathrm{~s}, 1 \mathrm{H}), 9.28(\mathrm{~d}, J=1.4 \mathrm{~Hz}, 1 \mathrm{H}), 8.92$ $(\mathrm{d}, J=2.5 \mathrm{~Hz}, 1 \mathrm{H}), 8.80(\mathrm{dd}, J=2.5,1.4 \mathrm{~Hz}, 1 \mathrm{H}), 7.80(\mathrm{~d}, J=9.0 \mathrm{~Hz}, 2 \mathrm{H}), 6.95(\mathrm{~d}, J=9.0 \mathrm{~Hz}, 2 \mathrm{H}), 3.75$ $(\mathrm{s}, 3 \mathrm{H}) .{ }^{13} \mathrm{C}$ NMR $\left(125 \mathrm{MHz}\right.$, DMSO- $\left.d_{6}\right) \delta: 161.2,155.9,147.5,145.2,143.9,143.2,131.2,122.0,113.8,55.2$. HRMS $m / z$ calcd for $\mathrm{C}_{12} \mathrm{H}_{11} \mathrm{~N}_{3} \mathrm{O}_{2}[\mathrm{M}+\mathrm{H}]^{+} 230.0851$, found 230.0843 .

$\mathrm{N}$-(4-Fluorophenyl)pyrazine-2-carboxamide (37). White microcrystals (98\%); m.p. $155-157^{\circ} \mathrm{C}$ (Lit. m.p. 154-155 $\left.{ }^{\circ} \mathrm{C}[72]\right) .{ }^{1} \mathrm{H}$ NMR $\left(500 \mathrm{MHz}, \mathrm{DMSO}-d_{6}\right) \delta: 10.82(\mathrm{~s}, 1 \mathrm{H}), 9.30(\mathrm{~d}, J=1.4 \mathrm{~Hz}, 1 \mathrm{H}), 8.97(\mathrm{~d}, J=2.5 \mathrm{~Hz}$, $1 \mathrm{H}), 8.81(\mathrm{dd}, J=2.5,1.4 \mathrm{~Hz}, 1 \mathrm{H}), 8.14-7.69(\mathrm{~m}, 2 \mathrm{H}), 7.24-7.19(\mathrm{~m}, 2 \mathrm{H}) .{ }^{13} \mathrm{C}$ NMR $\left(125 \mathrm{MHz}\right.$, DMSO- $\left.d_{6}\right) \delta$ : 161.6, 159.5, 157.6, 147.7, 144.9, 144.0, 143.2, 134.6, 122.5, 115.3, 115.2. HRMS $m / z$ calcd for $\mathrm{C}_{11} \mathrm{H}_{8} \mathrm{FN}_{3} \mathrm{O}$ $[\mathrm{M}+\mathrm{H}]^{+}$218.0651, found 218.0664.

2,2-Dichloro- $\mathrm{N}$-( -tolyl) acetamide (39). White microcrystals (85\%); m.p. $157-159{ }^{\circ} \mathrm{C}$ (Lit. m.p. 159-160 $\left.{ }^{\circ} \mathrm{C}[74]\right) .{ }^{1} \mathrm{H}$ NMR (500 MHz, DMSO- $\left.d_{6}\right) \delta: 10.56(\mathrm{~s}, 1 \mathrm{H}), 7.48(\mathrm{~d}, J=8.4 \mathrm{~Hz}, 2 \mathrm{H}), 7.17$ $(\mathrm{d}, J=8.4 \mathrm{~Hz}, 2 \mathrm{H}), 6.58(\mathrm{~s}, 1 \mathrm{H}), 2.27(\mathrm{~s}, 3 \mathrm{H}) .{ }^{13} \mathrm{C}$ NMR $\left(125 \mathrm{MHz}\right.$, DMSO- $\left.d_{6}\right) \delta: 161.5,135.0,133.8,129.4$, 129.4, 119.8, 119.8, 67.3, 20.5. HRMS $\mathrm{m} / z$ calcd for $\mathrm{C}_{9} \mathrm{H}_{9} \mathrm{Cl}_{2} \mathrm{NO}[\mathrm{M}+\mathrm{H}]^{+}$218.0061, found 218.0057.

2,2-Dichloro-N-(4-fluorophenyl) acetamide (40). White microcrystals (80\%); m.p. $130-132{ }^{\circ} \mathrm{C}$ (Lit. m.p. $\left.134-135^{\circ} \mathrm{C}[74]\right) .{ }^{1} \mathrm{H}$ NMR $\left(500 \mathrm{MHz}, \mathrm{DMSO}-d_{6}\right) \delta: 10.71(\mathrm{~s}, 1 \mathrm{H}), 7.71-7.55(\mathrm{~m}, 2 \mathrm{H}), 7.24-7.19(\mathrm{~m}, 2 \mathrm{H})$, 6.59 (s, $1 \mathrm{H}) .{ }^{13} \mathrm{C}$ NMR $\left(126 \mathrm{MHz}\right.$, DMSO-d $\left.d_{6}\right) \delta: 161.7,159.7,133.9,121.8,121.7,115.8,115.6,67.3$. HRMS $\mathrm{m} / z$ calcd for $\mathrm{C}_{8} \mathrm{H}_{6} \mathrm{Cl}_{2} \mathrm{FNO}[\mathrm{M}+\mathrm{H}]^{+}$221.9810, found 221.9813 .

2,2-Dichloro-N-(4-chlorophenyl) acetamide (41). White microcrystals (80\%); m.p. $143-145^{\circ} \mathrm{C}$ (Lit. m.p. 141-142 ${ }^{\circ} \mathrm{C}[74]$ ). ${ }^{1} \mathrm{H}$ NMR (500 MHz, DMSO- $\left.d_{6}\right) \delta: 10.79(\mathrm{~s}, 1 \mathrm{H}), 7.63(\mathrm{~d}, J=8.8 \mathrm{~Hz}, 2 \mathrm{H}), 7.43$ $(\mathrm{d}, J=8.8 \mathrm{~Hz}, 2 \mathrm{H}), 6.59(\mathrm{~s}, 1 \mathrm{H}) .{ }^{13} \mathrm{C}$ NMR $\left(125 \mathrm{MHz}, \mathrm{DMSO}-d_{6}\right) \delta: 161.8,136.5,128.9,128.3,128.3,121.4$, 121.4, 67.2. HRMS $m / z$ calcd for $\mathrm{C}_{8} \mathrm{H}_{6} \mathrm{Cl}_{3} \mathrm{NO}[\mathrm{M}+\mathrm{H}]^{+}$237.9515, found 237.9550.

\subsection{General Methods for Preparation of 2-Substituted Benzimidazoles}

In a typical procedure, a mixture of $o$-phenylenediamine (1 equiv.) and acylbenzotriazole (1 equiv.) was subjected to microwave irradiation $\left(20 \mathrm{~W}, 50^{\circ} \mathrm{C}\right)$ in water $(3 \mathrm{~mL})$ for $1 \mathrm{~h}$. After completion of the reaction, aqueous $4 \mathrm{~N} \mathrm{HCl}$ was added and the precipitates were filtered, followed by washing with water. The isolated products were recrystallized in ethanol to get the desired benzimidazoles in pure form. Benzotriazoles could be recovered from the aqueous layer by $\mathrm{pH}$-controlled acidification.

2-Phenyl-1H-benzo[d]imidazole (52). White microcrystals (82\%); m.p. 295-296 ${ }^{\circ} \mathrm{C}$ (lit. m.p. $295^{\circ} \mathrm{C}$ [75]). ${ }^{1} \mathrm{H}$ NMR $\left(500 \mathrm{MHz}\right.$, DMSO- $\left.d_{6}\right) \delta 8.32-8.30(\mathrm{~m}, 2 \mathrm{H}), 7.85-7.82(\mathrm{~m}, 2 \mathrm{H}), 7.75-7.70(\mathrm{~m}, 3 \mathrm{H}), 7.54-7.52(\mathrm{~m}, 2 \mathrm{H})$; ${ }^{13} \mathrm{C}$ NMR (125 MHz, DMSO- $d_{6}$ ) $\delta 151.2,143.8,134.9,130.2,129.5,128.9,126.4,122.5,121.6,118.9,111.3$. HRMS $m / z$ calcd for $\mathrm{C}_{13} \mathrm{H}_{10} \mathrm{~N}_{2}[\mathrm{M}+\mathrm{H}]^{+}$195.0844, found 195.0856 .

2-(4-Fluorophenyl)-1H-benzo[d]imidazole (53). White microcrystals (90\%); m.p. $249-251^{\circ} \mathrm{C}$ (lit. m.p. $\left.248{ }^{\circ} \mathrm{C}[75]\right) .{ }^{1} \mathrm{H}$ NMR $\left(500 \mathrm{MHz}, \mathrm{DMSO}-d_{6}\right) \delta 8.24-8.21(\mathrm{~m}, 2 \mathrm{H}), 7.60-7.59(\mathrm{~m}, 2 \mathrm{H}), 7.22-7.17(\mathrm{~m}, 4 \mathrm{H})$; ${ }^{13} \mathrm{C}$ NMR (125 MHz, DMSO- $\left.d_{6}\right) \delta 150.2,147.7,135.1,134.5,129.1,129.0,128.2,122.8,121.9,116.9,111.4$. HRMS $m / z$ calcd for $\mathrm{C}_{13} \mathrm{H}_{9} \mathrm{FN}_{2}[\mathrm{M}+\mathrm{H}]^{+}$213.0750, found 312.0746. 
2-(4-Chlorophenyl)-1H-benzo[d]imidazole (54). White crystalline solid (88\%); m.p. $299-301^{\circ} \mathrm{C}$ (lit. m.p. $\left.302{ }^{\circ} \mathrm{C}[75]\right) .{ }^{1} \mathrm{H}$ NMR $\left(500 \mathrm{MHz}\right.$, DMSO- $\left.d_{6}\right) \delta 12.72\left(\mathrm{~s}, 1 \mathrm{H}, \mathrm{D}_{2} \mathrm{O}\right.$ exchangable, $\left.>\mathrm{NH}\right), 8.11-7.93(\mathrm{~m}, 2 \mathrm{H})$, 7.46-7.43 (m, 4H), 7.16-7.14 (m, 2H); ${ }^{13} \mathrm{C}$ NMR (125 MHz, DMSO- $\left.d_{6}\right) \delta 150.1,146.9,135.0,134.6,129.1$, $128.7,128.6,127.8,121.8,122.0,117.2$. HRMS $m / z$ calcd for $\mathrm{C}_{13} \mathrm{H}_{9} \mathrm{ClN}_{2}[\mathrm{M}+\mathrm{H}]^{+} 229.0454$, found 229.0458 .

4-(1H-Benzo[d]imidazol-2-yl)phenol (55). Yellow microcrystals (86\%); m.p. 280-282 ${ }^{\circ} \mathrm{C}$ (lit. m.p. $\left.280{ }^{\circ} \mathrm{C}[75]\right) .{ }^{1} \mathrm{H}$ NMR $\left(500 \mathrm{MHz}, \mathrm{DMSO}-d_{6}\right) \delta 10.03\left(\mathrm{~s}, 1 \mathrm{H}, \mathrm{D}_{2} \mathrm{O}\right.$ exchangable, $\left.>\mathrm{NH}\right), 7.98(\mathrm{~d}, J=8.1 \mathrm{~Hz}$, $2 \mathrm{H}), 7.55-7.48(\mathrm{~m}, 2 \mathrm{H}), 7.20-7.14(\mathrm{~m}, 2 \mathrm{H}), 6.91(\mathrm{~d}, J=8.1 \mathrm{~Hz}, 2 \mathrm{H}) ;{ }^{13} \mathrm{C}$ NMR (125 MHz, DMSO- $\left.d_{6}\right)$ $\delta$ 165.0, 157.1, 144.2, 133.3, 127.5, 125.9, 123.7, 121.4, 120.1, 115.5. HRMS $m / z$ calcd for $\mathrm{C}_{13} \mathrm{H}_{10} \mathrm{~N}_{2} \mathrm{O}$ $[\mathrm{M}+\mathrm{H}]^{+}$211.0793, found 211.0792.

2-(4-Nitrophenyl)-1H-benzo[d]imidazole (56). Light yellow microcrystals (94\%); m.p. $318-320{ }^{\circ} \mathrm{C}$ (lit. m.p. $\left.317^{\circ} \mathrm{C}[75]\right) .{ }^{1} \mathrm{H}$ NMR $\left(500 \mathrm{MHz}, \mathrm{DMSO}-d_{6}\right) \delta 13.05$ (br s, $1 \mathrm{H}, \mathrm{D}_{2} \mathrm{O}$ exchangable, $>\mathrm{NH}$ ), 8.00 $(\mathrm{dd}, J=15.4,7.8 \mathrm{~Hz}, 2 \mathrm{H}), 7.87(\mathrm{td}, J=7.8,1.2 \mathrm{~Hz}, 1 \mathrm{H}), 7.76(\mathrm{td} J=7.8,1.4 \mathrm{~Hz}, 1 \mathrm{H}), 7.65-7.42(\mathrm{~m}, 2 \mathrm{H})$, $7.25(\mathrm{~d}, J=5.5 \mathrm{~Hz}, 2 \mathrm{H}) ;{ }^{13} \mathrm{C}$ NMR $\left(125 \mathrm{MHz}\right.$, DMSO- $\left.d_{6}\right) \delta 149.0,147.6,143.3,134.6,132.5,130.7,123.9$, 123.1, 121.9, 119.2, 111.5. HRMS $m / z$ calcd for $\mathrm{C}_{13} \mathrm{H}_{9} \mathrm{~N}_{3} \mathrm{O}_{2}[\mathrm{M}+\mathrm{H}]^{+} 240.0695$, found 240.0677.

2-(4-Methylphenyl)-1H-benzo[d]imidazole (57). White microcrystals (92\%); m.p. $274-276{ }^{\circ} \mathrm{C}$ (lit. m.p. $\left.275^{\circ} \mathrm{C}[75]\right) .{ }^{1} \mathrm{H}$ NMR $\left(500 \mathrm{MHz}, \mathrm{DMSO}-d_{6}\right) \delta 12.59\left(\mathrm{~s}, 1 \mathrm{H}, \mathrm{D}_{2} \mathrm{O}\right.$ exchangable, $\left.>\mathrm{NH}\right), 8.08(\mathrm{~d}, J=8.1 \mathrm{~Hz}$, 2H), 7.58-7.44 (m, 2H), $7.35(\mathrm{~d}, J=7.8 \mathrm{~Hz}, 2 \mathrm{H}), 7.12-7.11(\mathrm{~m}, 2 \mathrm{H}), 2.35(\mathrm{~s}, 3 \mathrm{H}) ;{ }^{13} \mathrm{C} \mathrm{NMR}(125 \mathrm{MHz}$, DMSO- $\left.d_{6}\right) \delta 151.4,139.4,129.4,127.4,126.4,121.9,116.3,21.0$. HRMS $m / z$ calcd for $\mathrm{C}_{14} \mathrm{H}_{12} \mathrm{~N}_{2}[\mathrm{M}+\mathrm{H}]^{+}$ 209.1000, found 209.1018.

2-(4-Trifluoromethylphenyl)-1H-benzo[d]imidazole (58). White microcrystals (83\%); m.p. $264-265^{\circ} \mathrm{C}$ (lit. m.p. $\left.263{ }^{\circ} \mathrm{C}[75]\right) ;{ }^{1} \mathrm{H}$ NMR $\left(500 \mathrm{MHz}\right.$, DMSO- $\left.d_{6}\right) \delta 12.79\left(\mathrm{~s}, 1 \mathrm{H}, \mathrm{D}_{2} \mathrm{O}\right.$ exchangable, $\left.>\mathrm{NH}\right), 8.34$ $(\mathrm{d}, J=8.8 \mathrm{~Hz}, 2 \mathrm{H}), 7.79-7.68(\mathrm{~m}, 2 \mathrm{H}), 7.61(\mathrm{~d}, J=8.8 \mathrm{~Hz}, 2 \mathrm{H}), 7.04-6.96(\mathrm{~m}, 2 \mathrm{H}) ;{ }^{13} \mathrm{C} \mathrm{NMR}(125 \mathrm{MHz}$, DMSO- $\left.d_{6}\right) \delta 160.3,151.3,138.2,127.7,126.1,124.5,122.4,121.4,115.1$. HRMS $m / z$ calcd for $\mathrm{C}_{14} \mathrm{H}_{9} \mathrm{~F}_{3} \mathrm{~N}_{2}$ $[\mathrm{M}+\mathrm{H}]^{+}$263.0718, found 263.0722.

2-(4-Methoxyphenyl)-1H-benzo[d]imidazole (59). White microcrystals (94\%); m.p. $227-229{ }^{\circ} \mathrm{C}$ (lit. m.p. $\left.228{ }^{\circ} \mathrm{C}[75]\right) ;{ }^{1} \mathrm{H}$ NMR $\left(500 \mathrm{MHz}, \mathrm{DMSO}-d_{6}\right) \delta 12.74\left(\mathrm{~s}, 1 \mathrm{H}, \mathrm{D}_{2} \mathrm{O}\right.$ exchangable, $\left.>\mathrm{NH}\right)$, $8.17(\mathrm{~d}, J=8.8 \mathrm{~Hz}, 2 \mathrm{H}), 7.59-7.57(\mathrm{~m}, 2 \mathrm{H}), 7.20-7.17(\mathrm{~m}, 2 \mathrm{H}), 7.04(\mathrm{~d}, J=8.8 \mathrm{~Hz}, 2 \mathrm{H}), 3.86(\mathrm{~s}, 3 \mathrm{H}) ;{ }^{13} \mathrm{C}$ NMR $\left(125 \mathrm{MHz}\right.$, DMSO- $\left.d_{6}\right) \delta 160.3,151.3,127.7,130.1,122.4,121.4,116.5,114.3,54.8$. HRMS $\mathrm{m} / z$ calcd for $\mathrm{C}_{14} \mathrm{H}_{12} \mathrm{~N}_{2} \mathrm{O}[\mathrm{M}+\mathrm{H}]^{+}$225.0950, found 225.0976.

2-(3,4,5-Trimethoxyphenyl)-1H-benzo[d]imidazole (60). Light yellow microcrystals (92\%); m.p. $259-260^{\circ} \mathrm{C}$ (lit. m.p. $\left.259^{\circ} \mathrm{C}[75]\right) .{ }^{1} \mathrm{H}$ NMR $\left(500 \mathrm{MHz}, \mathrm{DMSO}-d_{6}\right) \delta 7.78(\mathrm{~d}, J=7.8 \mathrm{~Hz}, 1 \mathrm{H}), 7.65(\mathrm{~d}, J=7.6 \mathrm{~Hz}, 1 \mathrm{H})$, $7.45(\mathrm{t}, J=7.2 \mathrm{~Hz}, 1 \mathrm{H}), 7.30(\mathrm{t}, J=7.2 \mathrm{~Hz}, 1 \mathrm{H}), 7.01(\mathrm{~s}, 2 \mathrm{H}), 4.04(\mathrm{~s}, 6 \mathrm{H}), 3.88(\mathrm{~s}, 3 \mathrm{H}) ;{ }^{13} \mathrm{C} \mathrm{NMR}(125 \mathrm{MHz}$, DMSO- $\left.d_{6}\right) \delta 155.1,153.1,142.2,138.4,124.7,123.2,121.9,108.8,60.1,57.4$. HRMS $m / z$ calcd for $\mathrm{C}_{16} \mathrm{H}_{16} \mathrm{~N}_{2} \mathrm{O}_{3}$ $[\mathrm{M}+\mathrm{H}]^{+}$285.1161, found 285.1168 .

Supplementary Materials: The following are available online at http://www.mdpi.com/1420-3049/25/11/2501/s1, general experimental data and NMR spectra.

Author Contributions: Conceptualization, S.S.P. and M.E.; Investigation, T.S.I., I.A.S., S.S.P. and M.E.; Supervision, T.S.I., S.S.P., A.M.M.A.-M. and Z.K.M.A.-S.; Writing-Original draft, T.S.I. and S.S.P.; Writing-Review \& editing, T.S.I., I.A.S., S.S.P., A.M.M.A.-M., Z.K.M.A.-S., N.A.A. and H.Z.A.; Funding acquisition, T.S.I., S.S.P., N.A.A and H.Z.A. All authors have read and agreed to the published version of the manuscript.

Funding: This project was funded by the Deanship of Scientific Research (DSR), King Abdulaziz University, Jeddah, under grant No.(RG-8-166-41). The authors, therefore, gratefully acknowledge DSR technical and financial support.

Conflicts of Interest: The authors declare no conflict of interest.

\section{References}

1. Savanur, H.M.; Malunavar, S.S.; Prabhala, P.; Sutar, S.M.; Kalkhambkar, R.G.; Laali, K.K. Synthesis of diverse libraries of carboxamides via chemoselective $\mathrm{N}$-acylation of amines by carboxylic acids employing Brønsted acidic IL [BMIM(SO3H)][OTf]. Tetrahedron Lett. 2019, 60, 151159. [CrossRef] 
2. Humphrey, J.M.; Chamberlin, A.R. Chemical Synthesis of Natural Product Peptides: Coupling Methods for the Incorporation of Noncoded Amino Acids into Peptides. Chem. Rev. 1997, 97, 2243-2266. [CrossRef] [PubMed]

3. Scozzafava, A.; Owa, T.; Mastrolorenzo, A.; Supuran, C.T. Anticancer and antiviral sulfonamides. Curr. Med. Chem. 2003, 10, 925-953. [CrossRef] [PubMed]

4. Pace, V.; Holzer, W.; Olofsson, B. Increasing the Reactivity of Amides towards Organometallic Reagents: An Overview. Adv. Synth. Catal. 2014, 356, 3697-3736. [CrossRef]

5. Greenberg, A.; Breneman, C.M.; Liebman, J.F. The Amide Linkage: Structural Significance in Chemistry, Biochemistry, and Material Science; Wiley- Interscience: New York, NY, USA, 2000.

6. Panda, S.S.; Girgis, A.S.; Mishra, B.B.; Elagawany, M.; Devarapalli, V.; Littlefield, W.F.; Samir, A.; Fayad, W.; Fawzy, N.G.; Srour, A.M.; et al. Synthesis, computational studies, antimycobacterial and antibacterial properties of pyrazinoic acid-isoniazid hybrid conjugates. RSC Adv. 2019, 9, 20450-20462. [CrossRef]

7. Alcaide, B.; Almendros, P.; Aragoncillo, C. $\beta$-Lactams: Versatile building blocks for the stereoselective synthesis of non- $\beta$-Lactam products. Chem. Rev. 2007, 107, 4437-4492. [CrossRef] [PubMed]

8. Roughley, S.D.; Jordan, A.M. The medicinal chemist's toolbox: An analysis of reactions used in the pursuit of drug candidates. J. Med. Chem. 2011, 54, 3451-3479. [CrossRef]

9. Ishihara, K. Dehydrative condensation catalyses. Tetrahedron 2009, 65, 1085-1109. [CrossRef]

10. Lanigan, R.M.; Sheppard, T.D. Recent developments in amide synthesis: Direct amidation of carboxylic acids and transamidation reactions. Eur. J. Org. Chem. 2013, 2013, 7453-7465. [CrossRef]

11. Lundberg, H.; Tinnis, F.; Selander, N.; Adolfsson, H. Catalytic amide formation from non-activated carboxylic acids and amines. Chem. Soc. Rev. 2014, 43, 2714-2742. [CrossRef]

12. Sabatini, M.T.; Boulton, L.T.; Sneddon, H.F.; Sheppard, T.D. A green chemistry perspective on catalytic amide bond formation. Nat. Catal. 2019, 2, 10-17. [CrossRef]

13. Wang, X. Challenges and outlook for catalytic direct amidation reactions. Nat. Catal. 2019, 2, 98-102. [CrossRef]

14. Rathi, J.O.; Shankarling, G.S. Concentrated solar radiation aided energy efficient and chemoselective protocol for $\mathrm{N}$-acylation and $\mathrm{N}$-formylation reactions in aqueous medium. Sol. Energy 2019, 189, 471-479. [CrossRef]

15. Ghose, A.K.; Viswanadhan, V.N.; Wendoloski,J.J.J. A Knowledge-Based Approach in Designing Combinatorial or Medicinal Chemistry Libraries for Drug Discovery. 1. A Qualitative and Quantitative Characterization of Known Drug Databases. Comb. Chem. 1999, 1, 55-68. [CrossRef] [PubMed]

16. Carey, J.S.; Laffan, D.; Thomson, C.; Williams, M.T. Analysis of the reactions used for the preparation of drug candidate molecules. Org. Biomol. Chem. 2006, 4, 2337-2347. [CrossRef] [PubMed]

17. Wolf, R.; Brenner, S. An active amide group in the molecule of drugs that induce pemphigus: A casual or causal relationship? Dermatology 1994, 189, 1-4. [CrossRef] [PubMed]

18. Rajput, P.; Sharma, A. Synthesis and biological importance of amide analogues. J. Pharmacol. Med. Chem. 2018, 2, 22-31.

19. Katritzky, A.R.; He, H.-Y.; Suzuki, K. N-Acylbenzotriazoles: Neutral Acylating Reagents for the Preparation of Primary, Secondary, and Tertiary Amides. J. Org. Chem. 2000, 65, 8210-8213. [CrossRef]

20. Mali, S.M.; Bhaisare, R.D.; Gopi, H.N. Thioacids Mediated Selective and Mild N-Acylation of Amines. J. Org. Chem. 2013, 78, 5550-5555. [CrossRef]

21. Panda, S.S.; Dennis Hall, C.; Scriven, E.; Katritzky, A.R. Aminoacyl benzotriazolides: Versatile reagents for the preparation of peptides, their mimetics and conjugates. Aldrichimica Acta. 2013, 46, 43-55.

22. Allen, C.L.; Williams, J.M.J. Metal-catalyzed approaches to amide bond formation. Chem. Soc. Rev. 2011, 40, 3405-3415. [CrossRef] [PubMed]

23. Cossy, J.; Palegrosdemange, C. Convenient synthesis of amides from carboxylic acids and primary amines. Tetrahedron Lett. 1989, 30, 2771-2774. [CrossRef]

24. Spivey, A.C.; Arseniyadis, S. Nucleophilic catalysis by 4-(dialkylamino)pyridines revisited - The search for optimal reactivity and selectivity. Chem. Int. Ed. 2004, 43, 5436-5441. [CrossRef]

25. Taylor, J.E.; Jones, M.D.; Williams, J.M.J.; Bull, S.D. N-Acyl DBN tetraphenylborate salts as N-acylating agents. J. Org. Chem. 2012, 77, 2808-2818. [CrossRef] [PubMed]

26. Owston, N.A.; Parker, A.J.; Williams, J.M.J. Highly efficient ruthenium-catalyzed oxime to amide rearrangement. Org. Lett. 2007, 9, 3599-3601. [CrossRef] 
27. Ramalingan, C.; Park, Y.-T. Mercury-Catalyzed Rearrangement of Ketoximes into Amides and Lactams in Acetonitrile. J. Org. Chem. 2007, 72, 4536-4538. [CrossRef]

28. Yoo, W.J.; Li, C.J. Highly Efficient Oxidative Amidation of Aldehydes with Amine Hydrochloride Salts. J. Am. Chem. Soc. 2006, 128, 13064-13065. [CrossRef]

29. Ekoue-Kovi, K.; Wolf, C. One-pot oxidative esterification and amidation of aldehydes. Chem. Eur. J. 2008, 14, 6302-6315. [CrossRef]

30. Yang, X.; Birman, V.B. Acyl Transfer Catalysis with 1,2,4-Triazole Anion. Org. Lett. 2009, 11, 1499-1502. [CrossRef]

31. Miller, S.J. In Search of Peptide-Based Catalysts for Asymmetric Organic Synthesis. Acc. Chem. Res. 2004, 37, 601-610. [CrossRef]

32. Ishihara, K.; Kosugi, Y.; Akakura, M. Rational design of an L-histidine-derived minimal artificial acylase for the kinetic resolution of racemic alcohols. J. Am. Chem. Soc. 2004, 126, 12212-12213. [CrossRef] [PubMed]

33. Seliem, I.A.; Panda, S.S.; Girgis, A.S.; Nagy, Y.I.; George, R.F.; Fayad, W.; Fawzy, N.G.; Ibrahim, T.S.; Al-Mahmoudy, A.M.M.; Sakhuja, R.; et al. Design, synthesis, antimicrobial, and DNA gyrase inhibitory properties of fluoroquinolone-dichloroacetic acid hybrids. Chem. Biol. Drug Des. 2020, 95, 248-259. [CrossRef] [PubMed]

34. Panda, S.S.; Girgis, A.S.; Mishra, B.B.; Elagawany, M.; Devarapalli, V.; Littlefield, W.F.; Samir, A.; Fawzy, N.G.; Srour, A.M. Novel pyrazinoic acid-isoniazid conjugates with amino acid linker: Microwave assisted synthesis, anti-infective properties, and molecular modeling studies. RSC Adv. 2019, 9, 20450-20462.

35. Panda, S.S.; Asiri, A.M.; Elagawany, M.; Buchanan, D.D.; Torkian, B.; Bathala, K.; Thomas, S.J.; Capito, J.E.; Arshad, M.N.; Al-Romaizan, A.N. Efficient synthesis of pyrazinoic acid hybrid conjugates. SynOpen 2017, 1, 50-58. [CrossRef]

36. Katritzky, A.R.; Rachwal, S. Synthesis of Heterocycles Mediated by Benzotriazole. 1. Monocyclic Systems. Chem. Rev. 2010, 110, 1564-1610. [CrossRef]

37. Katritzky, A.R.; Rachwal, S. Synthesis of Heterocycles Mediated by Benzotriazole. 2. Bicyclic Systems. Chem. Rev. 2011, 111, 7063-7120. [CrossRef] [PubMed]

38. Katritzky, A.R.; Yao, G.; Lan, X.; Zhao, X. The conversion of secondary into tertiary amides using benzotriazole methodology. J. Org. Chem. 1993, 58, 2086-2093. [CrossRef]

39. Katritzky, A.R.; Strah, S.; Belyakov, S.A. The preparation of functionalized amines and amides using benzotriazole derivatives and organozinc reagents. Tetrahedron 1998, 54, 7167-7178. [CrossRef]

40. Katritzky, A.R.; El Khatib, M.; Bol'shakov, O.; Khelashvili, L.; Steel, P.J. Benzotriazol-1-yl-sulfonyl Azide for Diazotransfer and Preparation of Azidoacylbenzotriazoles. J. Org. Chem. 2010, 75, 6532-6539. [CrossRef]

41. Küçükbay, F.Z.; Küçükbay, H.; Tanc, M.; Supuran, C.T. Synthesis and carbonic anhydrase inhibitory properties of amino acid-coumarin/quinolinone conjugates incorporating glycine, alanine and phenylalanine moieties. J. Enzyme Inhib. Med. Chem. 2016, 31, 1198-1202. [CrossRef]

42. Laconde, G.; Amblard, M.; Martinez, J. Unexpected Reactivity of N-Acyl-Benzotriazoles with Aromatic Amines in Acidic Medium (ABAA Reaction). Eur. J. Org. Chem. 2019, 2019, 85-90. [CrossRef]

43. Denny, W.A.; Rewcastle, G.W.; Bauley, B.C. Potential antitumor agents. 59. Structure-activity relationships for 2-phenylbenzimidazole-4-carboxamides, a new class of minimal DNA-intercalating agents which may not act via topoisomerase II. J. Med. Chem. 1990, 33, 814-819. [CrossRef] [PubMed]

44. Seyhan, E.; Sultan, N.; Nilgun, A.; Noyanalpan, N. Synthesis and antimicrobial activity of 5-substituted 1-dialkylaminomethyl-2-arylbenzimidazole derivatives. Arzneim.-Forsch. 1997, 47, 410-412.

45. Gungor, T.; Fouquet, A.; Eulon, J.-M.; Provost, D.; Cazes, M.; Cloarec, A. Cardiotonic agents. Synthesis and cardiovascular properties of novel 2-arylbenzimidazoles and azabenzimidazoles. J. Med. Chem. 1992, 35, 4455-4463. [CrossRef] [PubMed]

46. Schiffmann, R.; Neugebauer, A.; Klein, C.D. Metal-mediated inhibition of Escherichia coli methionine aminopeptidase: Structure-activity relationships and development of a novel scoring function for metal-ligand interactions. J. Med. Chem. 2006, 49, 511-522. [CrossRef] [PubMed]

47. Preston, P.N. Benzimidazoles and congeneric tricyclic compounds. In The Chemistry of Heterocyclic Compounds; Weissberger, A., Taylor, E.C., Eds.; Wiley: New York, NY, USA, 1981; Volume 40, pp. 6-60.

48. Grimmett, M.R. Imidazoles and their benzo derivatives. In Comprehensive Heterocyclic Chemistry; Katritzky, A.R., Rees, C.W., Eds.; Pergamon: Oxford, England, 1984; Volume 5, pp. 457-487.

49. Benincori, T.; Sannicolo, F. New benzimidazole synthesis. J. Heterocycl. Chem. 1988, 25, 1029-1033. [CrossRef] 
50. Tumelty, D.; Cao, K.; Holmes, C.P. Traceless solid-phase synthesis of substituted benzimidazoles via a base-cleavable linker. Org. Lett. 2001, 3, 83-86. [CrossRef] [PubMed]

51. Bahrami, K.; Khodaei, M.M.; Naali, F. Mild and highly efficient method for the synthesis of 2-arylbenzimidazoles and 2-arylbenzothiazoles. J. Org. Chem. 2008, 73, 6835-6837. [CrossRef] [PubMed]

52. Panda, S.S.; Ibrahim, M.A.; Oliferenko, A.A.; Asiri, A.M.; Katritzky, A.R. Catalyst-free facile synthesis of 2-substituted benzothiazoles. Green Chem. 2013, 15, 2709-2712. [CrossRef]

53. Panda, S.S.; Jain, S.C. A greener protocol for the highly efficient synthesis of spiro-indoles via Schiff's bases. Monatsh. Chem. 2012, 143, 1187-1194. [CrossRef]

54. Ibrahim, M.A.; Panda, S.S.; Alamry, K.A.; Katritzky, A.R. Green, Catalyst-Free Synthesis of Mesalazine Conjugates. Synthesis 2013, 45, 3255-3258.

55. Meegalla, S.K.; Wall, M.J.; Chen, J.; Wilson, K.J.; Ballentine, S.K.; Desjarlais, R.L.; Schubert, C.; Crysler, C.S.; Chen, Y.; Molloy, C.J.; et al. Structure-based optimization of a potent class of arylamide FMS inhibitors. Bioorg. Med. Chem. Lett. 2008, 18, 3632-3637. [CrossRef]

56. Talanian, R.V.; Quinlan, C.; Trautz, S.; Hackett, M.C.; Mankovich, J.A.; Banach, D.; Ghayur, T.; Brady, K.D.; Wong, W.W. Substrate specificities of caspase family proteas. J. Biol. Chem. 1997, 272, 9677-9682. [CrossRef] [PubMed]

57. Fujita, Y.; Tsuda, Y.; Li, T.; Motoyama, T.; Takahashi, M.; Shimizu, Y.; Yokoi, T.; Sasaki, Y.; Ambo, A.; Kita, A.; et al. Development of Potent Bifunctional Endomorphin-2 Analogues with Mixed $\mu-/ \delta$-Opioid Agonist and $\delta$-Opioid Antagonist Properties. J. Med. Chem. 2004, 47, 3591-3599. [CrossRef] [PubMed]

58. Pelagatti, P.; Carcelli, M.; Calbiani, F.; Cassi, C.; Elviri, L.; Pelizzi, C.; Rizzotti, U.; Rogolino, D. Transfer Hydrogenation of Acetophenone Catalyzed by Half-Sandwich Ruthenium(II) Complexes Containing Amino Amide Ligands. Detection of the Catalytic Intermediates by Electrospray Ionization Mass Spectrometry. Organometallics 2005, 24, 5836-5844. [CrossRef]

59. Geurts, M.; Poupaert, J.H.; Scriba, G.K.E.; Lambert, D.M. N-(Benzyloxycarbonyl)Glycine Esters and Amides as New Anticonvulsants. J. Med. Chem. 1998, 41, 24-30. [CrossRef] [PubMed]

60. Song, W.; Dong, K.; Li, M. Visible Light-Induced Amide Bond Formation. Org. Lett. 2020, 22, 371-375. [CrossRef] [PubMed]

61. Elmore, D.T.; Toseland, P.A. Degradative Studies on Peptides and Proteins. IV. Formation of Salts of 2-Acylaminothiazol-5-Ones by Acid-Catalyzed Degradation of N-Acylthiocarbamoylpeptides and Their Behavior towards Nucleophilic Reagents. J. Chem. Soc. 1957, 2460-2466. [CrossRef]

62. Tortorella, V.; Bettoni, G. Optical Rotatory Dispersion Curves of N-(N-Oxido-2-Pyridyl)Amino Compounds. IV. Amino Amides. Gazz. Chim. Ital. 1968, 98, 324-330.

63. Nuijens, T.; Cusan, C.; Kruijtzer, J.A.W.; Rijkers, D.T.S.; Liskamp, R.M.J.; Quaedflieg, P.J.L.M. Enzymatic Synthesis of C-Terminal Arylamides of Amino Acids and Peptides. J. Org. Chem. 2009, 74, 5145-5150. [CrossRef] [PubMed]

64. Maekawa, K.; Kubo, K.; Igarashi, T.; Sakurai, T. Electron Transfer-Initiated Asymmetric Photocyclization of Chiral Auxiliary-Substituted N-Acyl- $\alpha$-Dehydro(1-Naphthyl)Alaninamides to the Corresponding 3,4-Dihydrobenzo[f]Quinolinone Derivatives. Tetrahedron 2005, 61, 11211-11224. [CrossRef]

65. Abernethy, J.L.; Howell, F.G.; Ledesma, A.; Doose, D.; Everett, R. Behavior of Amides of N-Acylamino Acids toward Aniline and Substituted Anilines under Papain Catalysis. Tetrahedron 1975, 31, 2659-2662. [CrossRef]

66. Pettit, G.R.; Srirangam, J.K.; Barkoczy, J.; Williams, M.D.; Boyd, M.R.; Hamel, E.; Pettit, R.K.; Hogan, F.; Bai, R.; Chapuis, J.-C.; et al. Antineoplastic agents 365. Dolastatin 10 SAR probes. Anticancer. Drug Des. 1998, 13, 243-277. [PubMed]

67. Lampariello, L.R.; Peruzzi, D.; Sega, A.; Taddei, M. Some Observations on the Preparation of Amides and Their Reduction to Amines in Ionic Liquids. Lett. Org. Chem. 2005, 2, 265-270. [CrossRef]

68. Elzein, E.; Ibrahim, P.; Palle, V.; Rehder, K.; Zablocki, J.A. 1-akan-2-ol substituted piperazine and piperidine compounds. PCT Int Appl. Patent WO2005061470A1, 7 July 2005.

69. Pfleiderer, G.; Celliers, P.G.; Stanulovic, M.; Wachsmuth, E.D.; Determann, H.; Braunitzer, G. Properties and Analytical Application of the Kidney-Particle Aminopeptidase. Biochem. Z. 1964, 340, 552-564.

70. Antoine, M.; Marchand, P.; Le Baut, G.; Czech, M.; Baasner, S.; Gunther, E. Side Chain Modifications of (Indol-3-Yl)Glyoxamides as Antitumor Agents. J. Enzyme Inhib. Med. Chem. 2008, 23, 686-695. [CrossRef]

71. Orsy, G.; Fülöp, F.; Mándity, I.M. N-Acetylation of Amines in Continuous-Flow with Acetonitrile-No Need for Hazardous and Toxic Carboxylic Acid Derivatives. Molecules 2020, 25, 1985. [CrossRef] 
72. Dolezal, M.; Cmedlova, P.; Palek, L.; Vinsova, J.; Kunes, J.; Buchta, V.; Jampilek, J.; Kralova, K. Synthesis and Antimycobacterial Evaluation of Substituted Pyrazinecarboxamides. Eur. J. Med. Chem. 2008, 43, 1105-1113. [CrossRef]

73. Robba, M. Certain Derivatives of Diazines. I. Synthesis of Nitriles of Diazines. Ann. Chim. 1960, 5, 351-379.

74. Yang, Y.; Shang, P.; Cheng, C.; Wang, D.; Yang, P.; Zhang, F.; Li, T.; Lu, A.; Zhao, Y. Novel N-Phenyl Dichloroacetamide Derivatives as Anticancer Reagents: Design, Synthesis and Biological Evaluation. Eur. J. Med. Chem. 2010, 45, 4300-4306. [CrossRef]

75. Panda, S.S.; Jain, S.C. Synthesis of 2-Arylbenzimidazoles in Water. Synth. Commun. 2011, 41, 729-735. [CrossRef]

Sample Availability: Samples of the compounds are available from the authors.

(C) 2020 by the authors. Licensee MDPI, Basel, Switzerland. This article is an open access article distributed under the terms and conditions of the Creative Commons Attribution (CC BY) license (http://creativecommons.org/licenses/by/4.0/). 